Provided for non-commercial research and education use. Not for reproduction, distribution or commercial use.

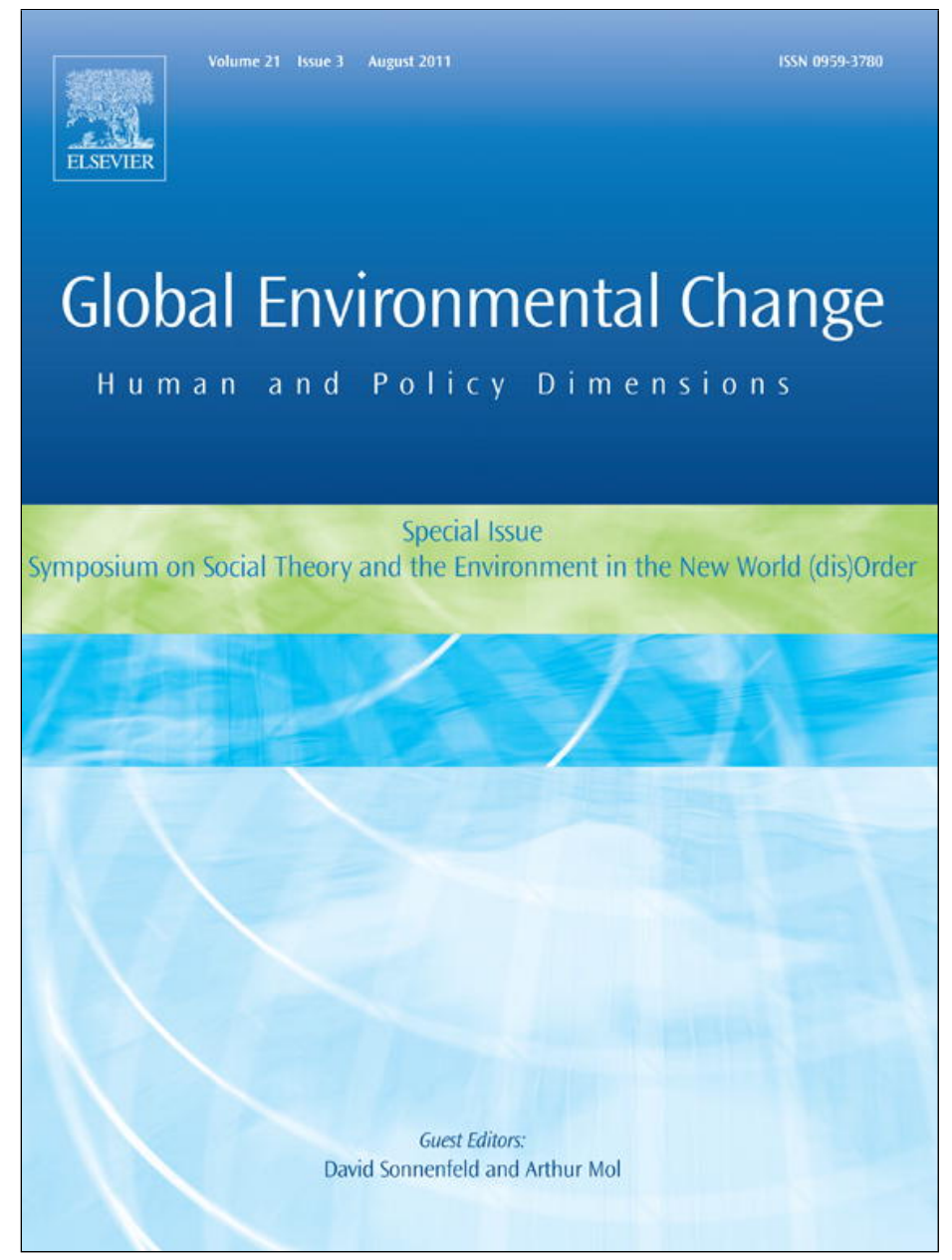

This article appeared in a journal published by Elsevier. The attached copy is furnished to the author for internal non-commercial research and education use, including for instruction at the authors institution and sharing with colleagues.

Other uses, including reproduction and distribution, or selling or licensing copies, or posting to personal, institutional or third party websites are prohibited.

In most cases authors are permitted to post their version of the article (e.g. in Word or Tex form) to their personal website or institutional repository. Authors requiring further information regarding Elsevier's archiving and manuscript policies are encouraged to visit:

http://www.elsevier.com/copyright 


\title{
Public responses to climate change: The role of deliberation in building capacity for adaptive action
}

\author{
Kersty Hobson ${ }^{\mathrm{a}, *}$, Simon Niemeyer ${ }^{\mathrm{b}, 1}$ \\ ${ }^{a}$ The University of Oxford, The Environmental Change Institute, School of Geography and the Environment, South Parks Road, Oxford OX1 3QY, United Kingdom \\ ${ }^{\mathrm{b}}$ The Australian National University, Research School of Social Sciences, Coombs Building (9), The Australian National University, Canberra ACT 0200, Australia
}

\section{A R T I C L E I N F O}

\section{Article history:}

Received 8 February 2011

Received in revised form 2 May 2011

Accepted 4 May 2011

Available online 12 June 2011

\section{Keywords:}

Deliberation

Q methodology

Adaptive capacity

\begin{abstract}
A B S T R A C T
Public deliberative platforms have been argued as potentially beneficial in fostering adaptive capacity to respond to climate change. However, little is known about the veracity of such claims, and indeed how deliberation and adaptive capacity can and do intersect. In response, this paper reports on findings from a project into public responses to climate change in the Australian Capital Region. It utilises quantitative analysis-in the form of $\mathrm{Q}$ methodology-and qualitative analysis, to compare discourses that emerged from individual scenario-based interviews with those that emerged at the end of a 4-day public deliberative process. It shows that while the scenario interviews had an impact on participants, this impact is not sustained. By contrast, the deliberative process gave rise to new discourses, one of which (labelled 'Collective Action Imperative') is argued as indicative of a potentially constructive personal and collective adaptive capacity. However, advocating deliberative processes still requires caution, as less adaptive discourses prevailed, suggesting strong governance signals and leadership are still essential for fostering a positive public response to the challenges of climate change.
\end{abstract}

(c) 2011 Elsevier Ltd. All rights reserved.

\section{Introduction}

The argument that a broad policy and practice 'response space' (Tompkins and Adger, 2003) is required to meet the challenges of current and future climate change is now well-made. However, questions of how to stimulate and sustain an array of positive collective and individual responses remain contentious and challenging. Of late, one area receiving both political and academic attention is the inclusion of publics into debates about, and enactments of, climate change mitigation and adaptation policies and practices (Tompkins et al., 2010), including the use of deliberative processes (such as Citizens' Juries or Deliberative Polling) to debate, for example, policy options for proactive adaptation strategies (Few et al., 2007).

The deployment of deliberative processes-which is the subject of this paper-is positioned within calls for greater public dialogue and engagement around climate change (Marx et al., 2007; Moser, 2010): in particular, arguments that:

'there is a requirement for governance mechanisms that can meaningfully acknowledge and negotiate the complexity

\footnotetext{
* Corresponding author. Tel.: +44 01865 275863; fax: +44 01865275850

E-mail addresses: kersty.hobson@ouce.ox.ac.uk (K. Hobson),

simon.niemeyer@anu.edu.au (S. Niemeyer).

${ }^{1}$ Tel.: +61026125 3605; fax: +61 0261252222 .
}

arising from the manifestation of diverse values-for example, deliberative platforms for adaptive action involving wide sets of stakeholders.' (Adger et al., 2009: 350).

Such arguments draw on the rationale of the broader 'deliberative turn' in environmental decision-making practices and research (Dryzek, 1997; Smith, 2003). However, to what extent and in what ways deliberative processes can and do build public adaptive capacity remains an open question, which requires further empirical scrutiny (Berkhout, 2010).

In response, this paper discusses research into public perceptions of, and reactions to, climate change in the Australian Capital Region (ACR). It examines what deliberation actually "does" via shifts in discourses, compared to discursive shifts amongst members of the public exposed to climate change information, but not deliberation. It begins with a brief discussion of the relevance of an 'adaptive capacity' framing, then outlines research design and methodology. The following section discusses the outcomes of 103 semi-structured interviews with residents of the ACR into potential climate change impacts in their region, drawing on both quantitative data from $\mathrm{Q}$ methodology and qualitative data from interview transcription and analysis. Then, comparative data is discussed for participants who took part in both interviews and a deliberative process, to examine similarities and differences in discursive shifts. Finally, this paper discusses these findings in 
terms of claims made about the role of deliberation in building public adaptive capacity to respond to climate change.

\section{Investigating adaptive capacity: what questions to ask of deliberation?}

Within the recent and growing literature, adaptive capacity is argued as an integral facet of socio-ecological system resilience (Folke et al., 2002), defined as a system adjusting positively to take advantage and/or cope with the impacts of a changing climate (Gallopin, 2006). Adaptive capacity is claimed to be a vital component of successful adaptive action, in conjunction with the societal distribution of these capacities (Adger et al., 2005), made up of numerous 'determinants' that are partially interdependent, and vary across space, time (Smit and Wandel, 2006; see also Brooks et al., 2005) and scale (e.g. Posey, 2009).

Determinants are often classified into social/institutional elements (e.g. social, human and political capital) and physical elements (e.g. infrastructure, material wealth and technology) (see Eakin and Lemos, 2006; Keskitalo et al., 2010). In turn, the former is segmented into human capital determinants such as learning, knowledge, and information, as well as the recognition of the necessity to adapt, which-along with political capital components such as trust-are argued as vital foundations for adaptive action. However, while a notable amount has been written about the economic, material and institutional facets of adaptive capacity, it is argued that less is known about its cognitive aspects, such as perceptions and motivations to take action (Lopez-Marrero, 2010), although there is a growing body of work here, particularly in relation to public opinion and responses to varied framings of the climate change issue (e.g. see Morton et al., 2011; Wood and Vedlitz, 2007).

In theory, deliberative processes may contribute positively to the fostering of aspects of these social determinants by, for example, encouraging learning and/or increasing feelings of personal efficacy and the recognition of climate change as a genuine problem. Although some evidence does exist for deliberation having such impacts on participants (see Thompson, 2008), there has been little interrogation of its effects in terms of building adaptive capacity around current and future climate change.

What then might be some apposite questions of ask of public deliberative processes, in terms of adaptive capacity? From analysis of the theoretical and empirical literature on the social determinants of adaptive capacity (e.g. Eakin and Lemos, 2006; Fazey et al., 2007; Folke et al., 2002, 2005; Hahn et al., 2006; Kalikoski et al., 2010; Lopez-Marrero, 2010; Milestad et al., 2010) the following questions were drawn out, to be posed of the ACR research.

- Recognition: Do participants increasingly recognise the need to adapt/take action around climate change?

- Knowledge: Do they have more knowledge about options and greater capacity to assess them?

- Motivation: Do participants express greater willingness and ability (of themselves and others) to mobilize around climate change?

- Personal efficacy: Do they feel more able to implement these options?

- Political efficacy: Do perceptions of political capital alter, in terms of trust in institutions and governance systems?

Before discussing the results of the ACR research vis-à-vis the above list of questions, the next section presents an overview of the project research design and methodology.

\section{Social responses to climate change in the ACR: project rationale and methodology}

The research discussed herein sought to gain more in-depth understanding of how members of the public currently perceive climate change, as such perceptions will shape (but do not

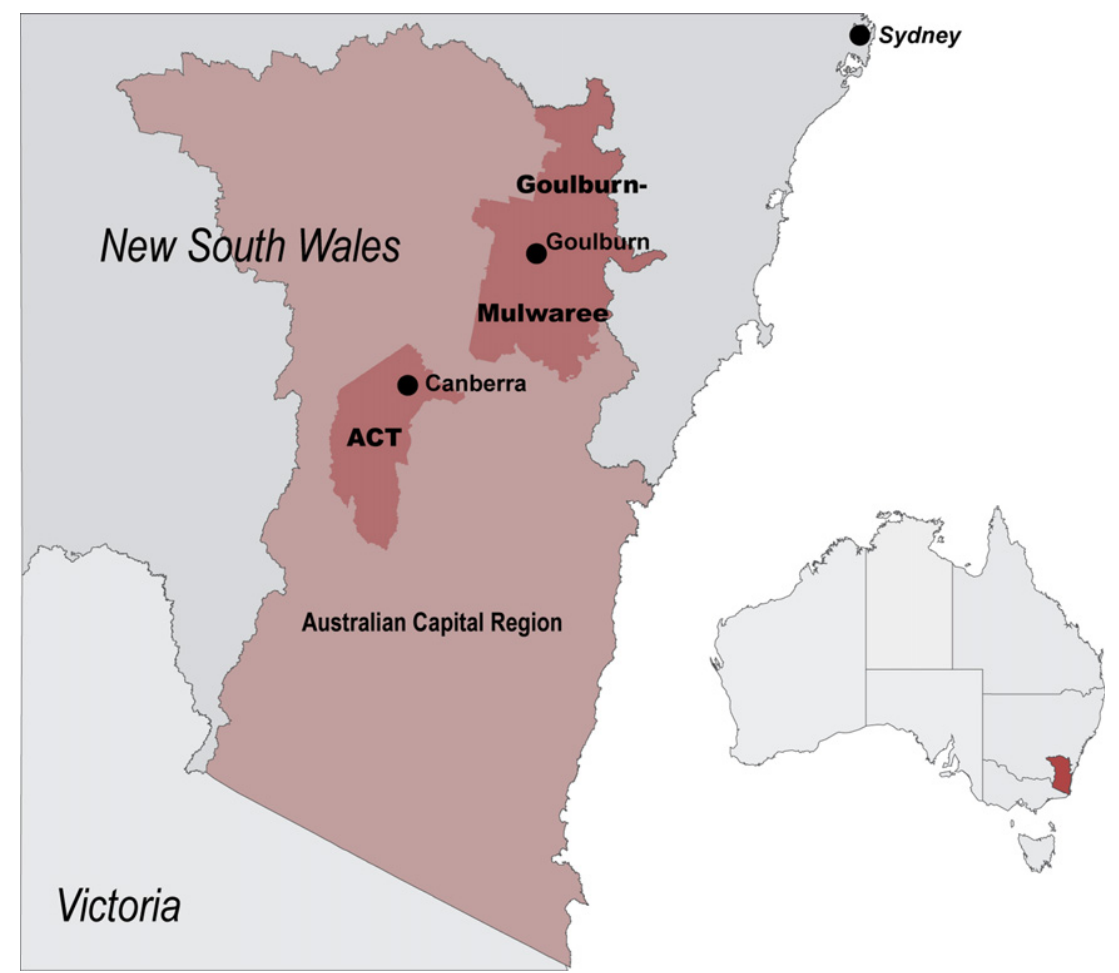

Fig. 1. The Australian Capital Region and case study areas. 


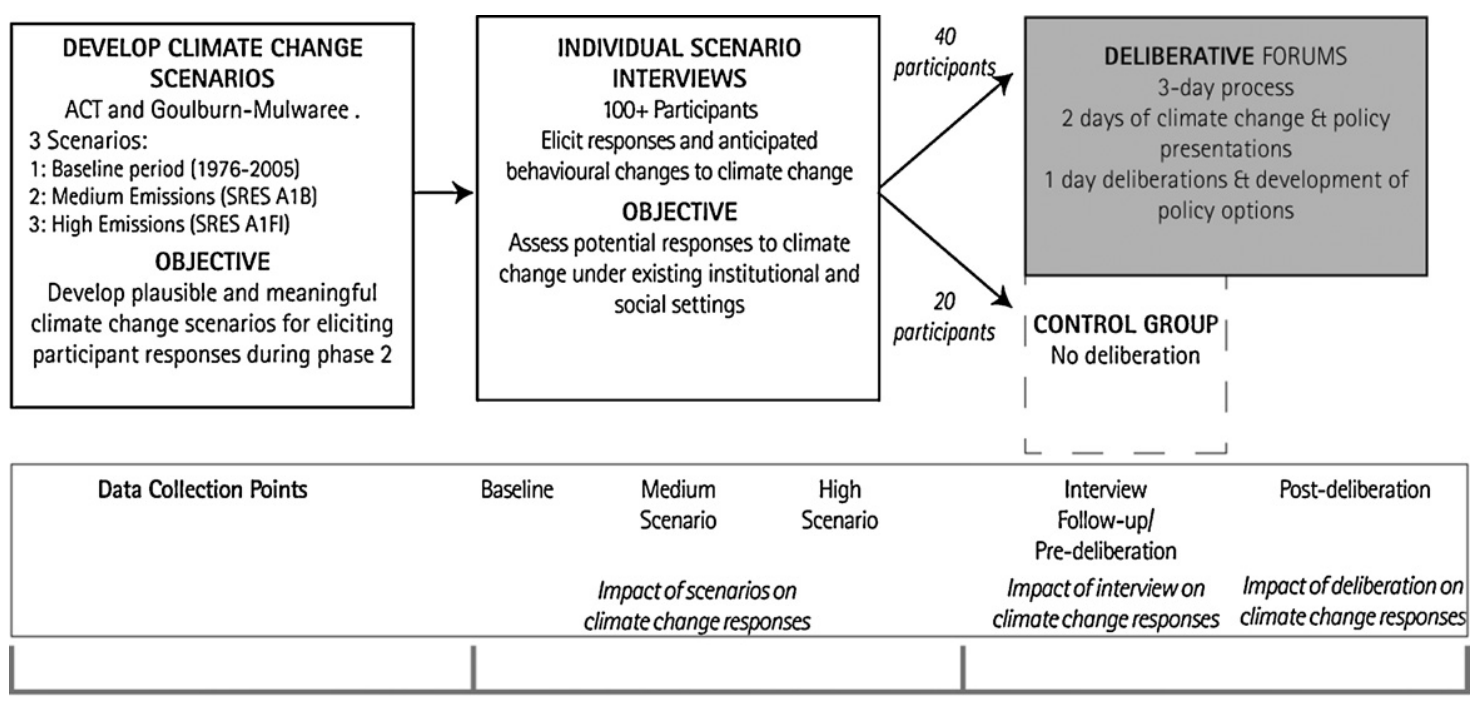

Phase 1

\section{Phase 2}

Phase 3

Fig. 2. ACR research design.

determine) future actions. While extensive data exists on projected changes to the climate, less is known about possible individual and collective behavioural responses to such changes. Thus, there is a need for intensive research that investigates responses to different climate change stimulus, to provide 'thick descriptions' (Adger et al., 2003) of how perceptions and reactions might play out.

However such research is not without methodological and epistemological challenges, e.g. how to present information about potential impacts of future climate change given the levels of uncertainty about actual climate changes impacts (Lorenzoni et al., 2006): and how to account for the numerous contingencies in decision-making processes that make modelling human futures near impossible (e.g. see Berkhout and Hertin, 2000; Vincent, 2007)? However, such challenges should not deter humanfocussed research, and in response, the ACR project explored social responses to climate change within two regions: the Australian Capital Territory (ACT) and the Goulburn-Mulwaree Shire (GMS) shown in Fig. 1. These case study areas were chosen as they share similar institutional and political contexts, but different demographic and economic profiles. The ACT is highly urbanised, and contains Australia's capital Canberra (population 340,000), with a high proportion of residents employed in Federal or State government. By contrast, GMS is a 1-h drive from Canberra, across the border into New South Wales. It is a predominantly rural area, with employment focussed on grazing agriculture, and with the regional town Goulburn (population 21,000) providing supporting services.

Fig. 2 outlines the key components of the ACR research design, split into 3 phases that spanned 2008 to 2010. The following subsections outline the main components of each phase, with subsequent discussion focusing on results form Phases 2 and 3.

\subsection{Phase 1: developing climate change scenarios}

This research constructed a series of climate scenarios to represent impacts of projected climate changes within the ACR over a time frame up to 2100 . The ACR regional scale was chosen as research suggests that finer-scale impact modelling may be more meaningful to individuals if they can connect it with the spaces and scales of their everyday lives (Shackley and Deanwood, 2002).

The scenarios were developed using the Commonwealth Scientific and Industrial Research Organisation's (CSIRO) OzClim model. ${ }^{2}$ They were based on 'medium' and 'high' emissions trajectories associated with the SRES A1B and the SRES A1FI scenarios respectively (see Appendix A for emissions trajectories and time slices). As a reference point, a Baseline scenario for 1990 was developed based on the average climate over a 30-year period (1976-2005). Two further scenarios (Medium and High) were then created with climate parameters produced for two timeline slices. The first time-slice was 2050: in addition, a second time-slice at 2100 was included.

The impacts on various climate parameters for the scenarios were then produced for the 2050 and 2100 time slices. These covered a range of climatic variables, e.g. temperature, rainfall, growing range for key species and climatic domain representation. In most cases the information was produced in map form, except where indicated as data. The changes to scenario parameters in map, graphical, and schematic form were animated between the time-slices. Finally, all the maps and data were translated into iWork'09 KeyNote presentations (one presentation per emissions trajectory, i.e. Baseline, Medium and High), to be used in interviews with members of the ACR public to gauge their reactions.

\subsection{Phase 2: measuring the impact of climate change through scenario interviews}

During May 2010 a total of 103 face-to-face interviews were held in the ACT and GMS. Interviewees were recruited via mail out invitations, sent to 2300 households in the ACR selected randomly from the electoral roll. A total of 262 people responded registered an interest in participating ( 188 from the ACT, 74 from the GMS: a response rate of $11 \%$ ).

The final 103 interviewees ( 72 from the ACT, 31 from the GMS) were selected by researchers, based on (a) responses to a questionnaire accompanying invitations that asked questions about beliefs and attitudes towards climate change; and (b) basic socio-demographic information, e.g. age and education. In terms of (a), the selection process involved a random stratification approach

\footnotetext{
${ }^{2}$ The CSIRO OzClim model contains patterns of regional changes in climate projected from 23 global climate models archived at the Program for Climate Model Diagnosis and Intercomparison (PCMDI). The model enables users to select from six SRES scenarios (taken from the 'Special Report on Emissions') and two commonly used $\mathrm{CO}_{2}$ concentration stabilisation scenarios to generate projections for any of the available global climate models (Garnaut, 2008; IPCC, 2000; Stern, 2006).
} 
Table 1

Summary of participants selected for participation in the climate change scenarios interviews and deliberative forum.

\begin{tabular}{|c|c|c|c|c|c|}
\hline & \multicolumn{2}{|l|}{ Numbers } & \multicolumn{2}{|c|}{ Percentages } & \multirow[t]{2}{*}{ Australian population } \\
\hline & Interview & Forum & Interview & Forum & \\
\hline \multicolumn{6}{|l|}{ Gender } \\
\hline Male & 57 & 21 & $55 \%$ & $60 \%$ & $49 \%$ \\
\hline Female & 46 & 14 & $45 \%$ & $40 \%$ & $51 \%$ \\
\hline \multicolumn{6}{|l|}{ Age } \\
\hline $18-29$ & 21 & 6 & $14 \%$ & $17 \%$ & $29 \%$ \\
\hline $30-44$ & 23 & 5 & $22 \%$ & $14 \%$ & $27 \%$ \\
\hline $45-59$ & 32 & 14 & $30 \%$ & $40 \%$ & $24 \%$ \\
\hline $60-75$ & 27 & 10 & $26 \%$ & $29 \%$ & $19 \%$ \\
\hline \multicolumn{6}{|l|}{ Highest education level } \\
\hline Junior secondary education & 8 & 2 & $8 \%$ & $6 \%$ & $13 \%$ \\
\hline Senior secondary education & 26 & 9 & $25 \%$ & $26 \%$ & $24 \%$ \\
\hline All diploma or certificate & 36 & 13 & $35 \%$ & $37 \%$ & $33 \%$ \\
\hline Bachelor degree & 22 & 9 & $21 \%$ & $26 \%$ & $16 \%$ \\
\hline Postgraduate study & 10 & 2 & $10 \%$ & $6 \%$ & $4 \%$ \\
\hline Other/NA & 1 & 0 & $1 \%$ & $0 \%$ & $9 \%$ \\
\hline
\end{tabular}

to capture a range of beliefs regarding the 'reality' of climate change, in an attempt to mirror as close as possible Australian public opinion (see Ong et al., 2010). This process also involved selecting across a range of demographic characteristics (gender, age, education level) to achieve a distribution reflecting the wider Australian population. The results are shown in Table 1, which also outlines the characteristics of the participants selected from to participate in the deliberative forum (see below).

As the table shows, there was an under-representation of individuals under 30 years old, and women. when both are compared to the broader Australian public. There was also an overrepresentation of individuals with a Bachelor degree or postgraduate education-in part because the ACT is the most educated demographic within Australia. These differences could only be partially stratified out in the participant selection, while maintaining a range of perspectives on climate change.

All interviews lasted for at least $2 \mathrm{~h}$, and were recorded for qualitative analysis purposes. Interviews followed a pre-established protocol, summarised in Table 2 .

Q methodology was used to gauge both current and possible future perceptions of climate change. $Q$ methodology is a now well-established approach to exploring an issue through the lens of discourses (Barry and Proops, 1999; Brown, 1980). Here, discourses can be understood as shared meanings that coalesce around particular 'story lines' (Dryzek, 1993, 1994, 1997; Dryzek and Niemeyer, 2008; Hajer, 1995). These story lines enable the expression of personal beliefs and attitudes in ways that others will comprehend (Bankoff, 2001). At the same time, they are fundamental to shaping individuals' beliefs and attitudes (Darier, 1999) making them concurrently shared and personal ways of comprehending the world. Indeed, Q methodology has been used to identify key discourses around ecological citizenship and climate change in Canada (Wolf et al., 2009), as well as feelings of salience and personal efficacy around climate change in the UK (Lorenzoni et al., 2007). However, while most studies using Q methodology identify key discourses as static entities, this research used it as a dynamic tool to track the discursive changes over research Phases 2 and 3. The aim was to collect data about the social dynamics of responses to the issue; how it might unfold as climate changes; and how both of these factors might differ under deliberative conditions.

The application of Q methodology involved collecting statements about climate change adaptation from preliminary interviews, mass media, and parliamentary records. Then a subsample of 33 statements was selected after being piloted in late 2009 (see Appendix B for full statement list). The $\mathrm{Q}$ interview involved participants sorting the 33 statements along a scale from +5 (agree strongly) to -5 (disagree strongly): a process called a ' $Q$ Sort'. The resulting $\mathrm{Q}$ sorts were analysed using inverted factor analysis to identify the shared discourses (or factors, to use the language of $Q$ methodology).

Thus, Q Sorts were performed by all 103 interviewees (Phase 2) after viewing each scenario presentation (Baseline, Medium, High), as well as by all participants at the start and end of the deliberative process (Phase 3). Finally, in October 2010, 20 individuals who had taken part in the scenario interviews only (i.e. not the deliberative process) were reinterviewed, to examine whether any noted changes during the interviews had been sustained or altered in the ensuing months (Phase 3).

\subsection{Phase 3: the deliberative forum}

After the above interviews were completed, 40 individuals were selected to participate in a deliberative forum to take place at the

Table 2

Protocol for scenario interviews.

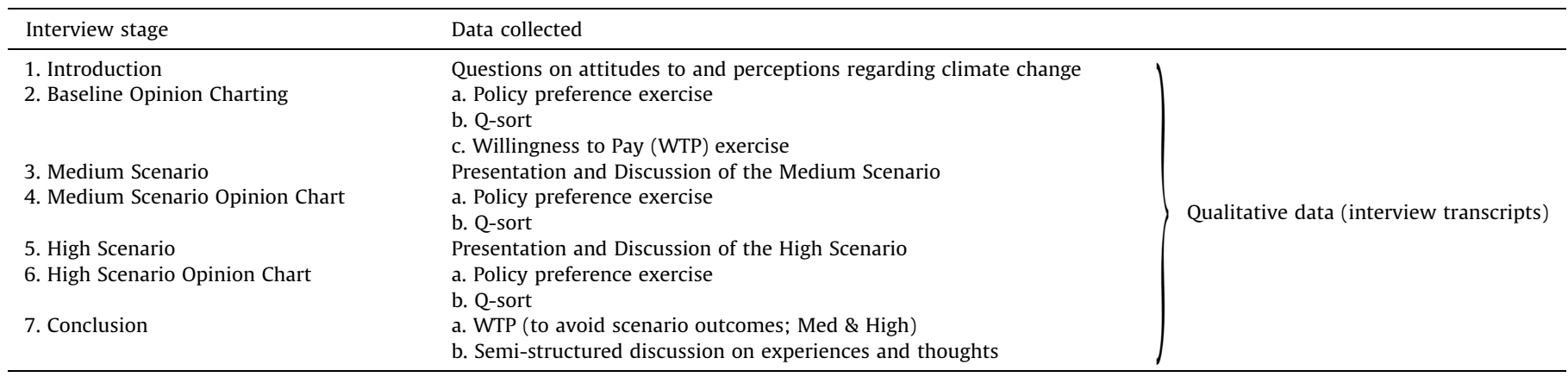


end of May 2010, using a random stratification of the above interviewees. The aim here was to achieve a discursively representative sample (Dryzek and Niemeyer, 2008) across the main discourses identified in Phase 2 (outlined below), as well as broad demographic representation across the categories shown in Table 1 . The relatively low proportion of females (40\%) and younger participants $(>30)$ reflects the difficulty in recruiting from these groups for the research, particularly in respect to participation in a demanding 3-day process. But it also reflects the difficulty in achieving a discursively representative sample within these demographic constraints, particularly in respect to individuals who do not believe that climate change is happening or a problem (who tend to fall into discourse A, reported below). For example, climate sceptics in our sample are predominantly older men although attempts were made to find sceptics within other categories to participate in the deliberative forum. Thus, although the selection process used has shortcomings, one advantage of the 'discursive' approach is that it helps to ensure a range of attitudes amongst the participants that cannot be adequately captured using demographic categories alone (Dryzek and Niemeyer, 2008).

of the 40 individuals invited, 35 completed the forum, which ran for 4 days in total. For the first 2 days (Friday 28 and Saturday 29 May) all participants talked, listened and ate together. On day 3 , they were split into their respective geographical locations, as the focus of discussion was policy responses and the ACT and GMS have different political and institutional contexts. Thus, on Sunday 30 May all GMS participants met in Goulburn: and on Saturday 5 June, all ACT participants met in Canberra. A timetable for these 4 days is shown in Table 3.

Overall the forum aimed to enable participants to learn more about the issues featured in the scenarios through presentations by academic and policy experts. In addition, it aimed to provide the opportunity for participants to debate with each other and question experts about the facts and values underpinning climate change debates via 'communicative learning' (Petts, 2007): argued as key to fostering positive action on issues such as climate change (Marx et al., 2007).

\section{Charting climate change discourse: results from scenario interviews}

The remainder of this paper discusses the results from the $Q$ sorts undertaken in Phases 2 and 3, examining the different impacts the scenario interviews and deliberation had on potentially fostering adaptive capacity.

To begin, the analysis of $\mathrm{Q}$ sorts during the Phase 2 scenario interviews revealed four main discourses, labelled here as:

\section{A. Self-assured Scepticism \\ B. Governance Imperative \\ C. Assured Pragmatism \\ D. Alarmed Defeatism}

The main characteristics of each of the discourses are schematically represented in Fig. 3 in the form of four overlapping spheres. Each sphere contains the main elements of each discourse as paraphrased statements used in the Q sort: the numbers in brackets after each statement corresponds to its number in Appendix B. Features that are shared by two or more discourses are shown in the areas of overlap. The diagram is schematic, rather than precise or analytic. The spheres are drawn to permit the placement of statements according to whether they are associated with one or more discourses, based on the factor $z$-scores resulting from the inverted factor analysis.

The following discussion describes each of the discourses in turn.
Table 3

Timetable of the deliberative process.

\begin{tabular}{|c|c|c|}
\hline Day & Location & Activities \\
\hline 1 & $\begin{array}{l}\text { The Australian National } \\
\text { University, Canberra }\end{array}$ & $\begin{array}{l}\text { - Ice-breaker } \\
\text { - Initial Opinion Charting } \\
\text { - Setting deliberative ground-rules } \\
\text { - Presentations (science and socio-economic } \\
\text { aspects of climate change) } \\
\text { - Small group-break out sessions } \\
\text { and questions to the floor } \\
\text { - Group meal in the evening }\end{array}$ \\
\hline 2 & $\begin{array}{l}\text { The Australian National } \\
\text { University, Canberra }\end{array}$ & $\begin{array}{l}\text { - Presentations (bio-physical impacts } \\
\text { and international politics) } \\
\text { - Group exercise (adaptation and } \\
\text { mitigation) } \\
\text { - Group discussion approaches } \\
\text { to adaptation and mitigation }\end{array}$ \\
\hline \multirow[t]{3}{*}{3} & $\begin{array}{l}\text { Goulburn Workers' } \\
\text { Club, Goulburn, }\end{array}$ & $\begin{array}{l}\text { - Group deliberation: } \\
\text { priorities for action }\end{array}$ \\
\hline & $\begin{array}{l}\text { New South Wales } \\
\text { (15 Goulburn-Mulwaree } \\
\text { Participants) }\end{array}$ & $\begin{array}{l}\text { - Group deliberation: recommended } \\
\text { policy approaches }\end{array}$ \\
\hline & $\begin{array}{l}\text { The Australian National } \\
\text { University, Canberra } \\
\text { (20 ACT participants) }\end{array}$ & $\begin{array}{l}\text { - Feedback on recommendations from } \\
\text { local policy makers } \\
\text { - Finalizing recommendations } \\
\text { - Final Opinion Charting } \\
\text { - Feedback and reflection on process and } \\
\text { research }\end{array}$ \\
\hline
\end{tabular}

\subsection{Discourse A: Self-Assured Scepticism}

This discourse includes those individuals who do not believe in human-induced climate change or who believe that it is occurring but not anthropogenic. Many are doubtful about the veracity of climate science, and overall there is a belief that not enough information exists to sustain the anthropogenic argument: perspectives that arguably reflect the numerous barriers to climate change action identified elsewhere using Q methodology (Lorenzoni et al., 2007; Wolf et al., 2009). The following quote from one participant reflects this perspective:

"I remember when I grew up everyone was talking about global cooling. It's bizarre how in 20 years it has reversed." (Male, mid40s)

While such scepticism speaks to uncertainty surrounding climate change projections, participants loaded on this discourse have a strong 'meta-cognitive confidence' (Scannell and Grouzet, 2010) in their own conclusions. They do express concern about the planet and future generations and a willingness to 'do their bit'. But action, and, to some extent, a belief in climate change, is forestalled by profound lack of trust in existing institutions and key actors in the climate change debate, i.e. the media, government and scientists. Problematically, they want these actors to get on and "sort the issue out" while not trusting them to do so. However, such tensions are reconciled by the belief that climate change is not really a major issue and there is no need to panic, creating a general willingness to act underscored by justifiable reasons for inaction.

\subsection{Discourse B: Governance Imperative}

Discourse B most closely echoes the majority sentiment in the wider Australian community (Ong et al., 2010). It represents the view that climate change is a genuine anthropogenic phenomenon and that direct government action is required, as market forces alone will not be able to address the problem. As one participant loaded on this discourse commented:

"So if the government works in the public good, shouldn't they be the ones to lead the way, rather than business forces? Isn't 
A: Self-assured Scepticism

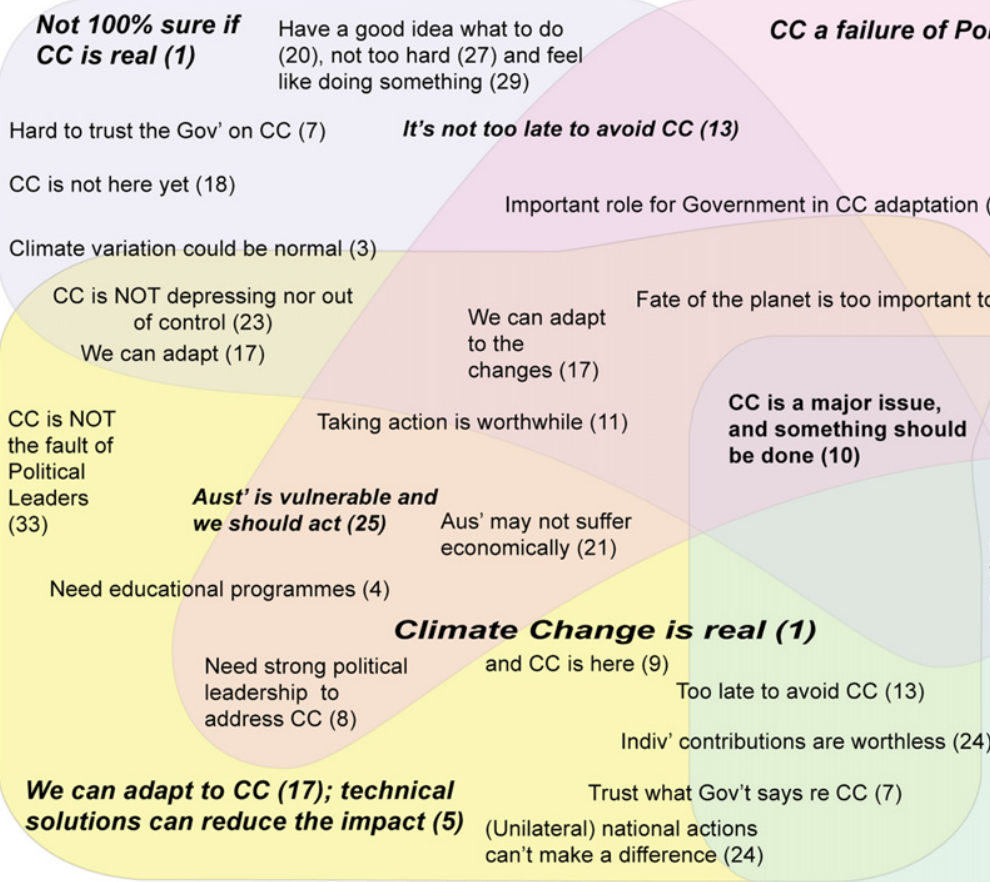

C: Assured Pragmatism
B: Governance Imperative$$
\text { \& laws (26) }
$$

Unilateral national action can make a difference (24)

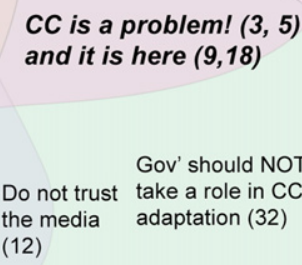
(12)

The response to $\mathrm{CC}$ is not going to be positive. The same mistakes will keep happening (2)

$C C$ is depressing and out of control (23)

D: Alarmed Defeatism

Fig. 3. Discourses from ACR scenario interviews.

there room to have more informed decisions rather than just economic?" (Female, early 20s)

In this discourse, a perceived failure of leadership was a significant feature, along with the belief that government efforts to engage people with climate change had been somewhat tokenistic. As one individual commented, when discussing the lack of twoway communication on this issue between government and the public, "If you really want to hear from the public, you have to invest in hearing from us" (Female, late 30s). Indeed, there was a strong feeling that it was the responsibility of the government to act: a feeling shared by many other Australian (e.g. see Ong et al., 2010). The serious and pressing nature of this issue was expressed by many associated with this discourse, often in quite dramatic tones, such as "If this was a war, we would have gone on to rations by now." (Female, mid 20s).

This resonates with the strong belief that Australia must take action, as it has both a pragmatic and moral imperative to act and lead on climate change policy. Indeed, participants associated with this discourse are willing to take personal action to address this issue, and believe that individuals can make a positive difference. In line with this, educational programmes are also favoured, associated with relative optimism about the impact they can have. However, this discourse was underpinned by the need for political leadership: without which, individuals are less likely themselves to respond to attempts to adapt to climate change.

\subsection{Discourse C: Assured Pragmatism}

Like discourse $\mathrm{B}$, discourse $\mathrm{C}$ accepts that climate change is real and anthropogenic. Much is shared with B yet it is slightly more indifferent to the need to take action because of technological optimism and also because (like A) there is a strong belief in our capacity to adapt. This position echoes discourses of 'ecological modernization' with a 'win-win' approach to addressing environmental issues (Janicke, 2008). As one participant stated:
"There's always going to be more improvement in technology, so I think we'll be able to find a way to get through [climate change]." (Male, early 20s)

In the face of this technological optimism, there is a good deal of cynicism about the potential for individual actions to have any real impact. There is also a sense that Australia has both an interest in, and a duty towards, finding a solution to this problem, but the emphasis is more on collective responses, under strong leadership thus providing a strong personal incentive not to take action (Lorenzoni et al., 2007).

\subsection{Discourse D: Alarmist Defeatism}

The final discourse embodies an emphatic belief that climate change is real and here, and a serious threat, a sentiment captured by the following quotes:

"We're looking at a six-degree rise by 2100 . That is where civilisation as we know it cannot cope." (Female, early 20s)

"We are well on the endangered species list and I'm not joking .. there is going to be total social and environmental collapse."

(Female, late 50s)

Discourse D thus echoes a catastrophic and apocalyptic view, wherein climate change marks the end of civilisation as we know it (Risby, 2008; Segnit and Ereaut, 2007). There is a strong sense of 'giving up' on measures such as education and a definite degree of pessimism about the possibility of mitigating climate change given the enormity of the challenge that is undergirded and perpetuated by global forces such as "Corporate Globalization" (as one participant labelled it): a sentiment that echoes Wolf et al.'s (2009) discourse of the 'Systemist' who argues that climate change is one symptom of a fundamental problem with the global modus operandi. 


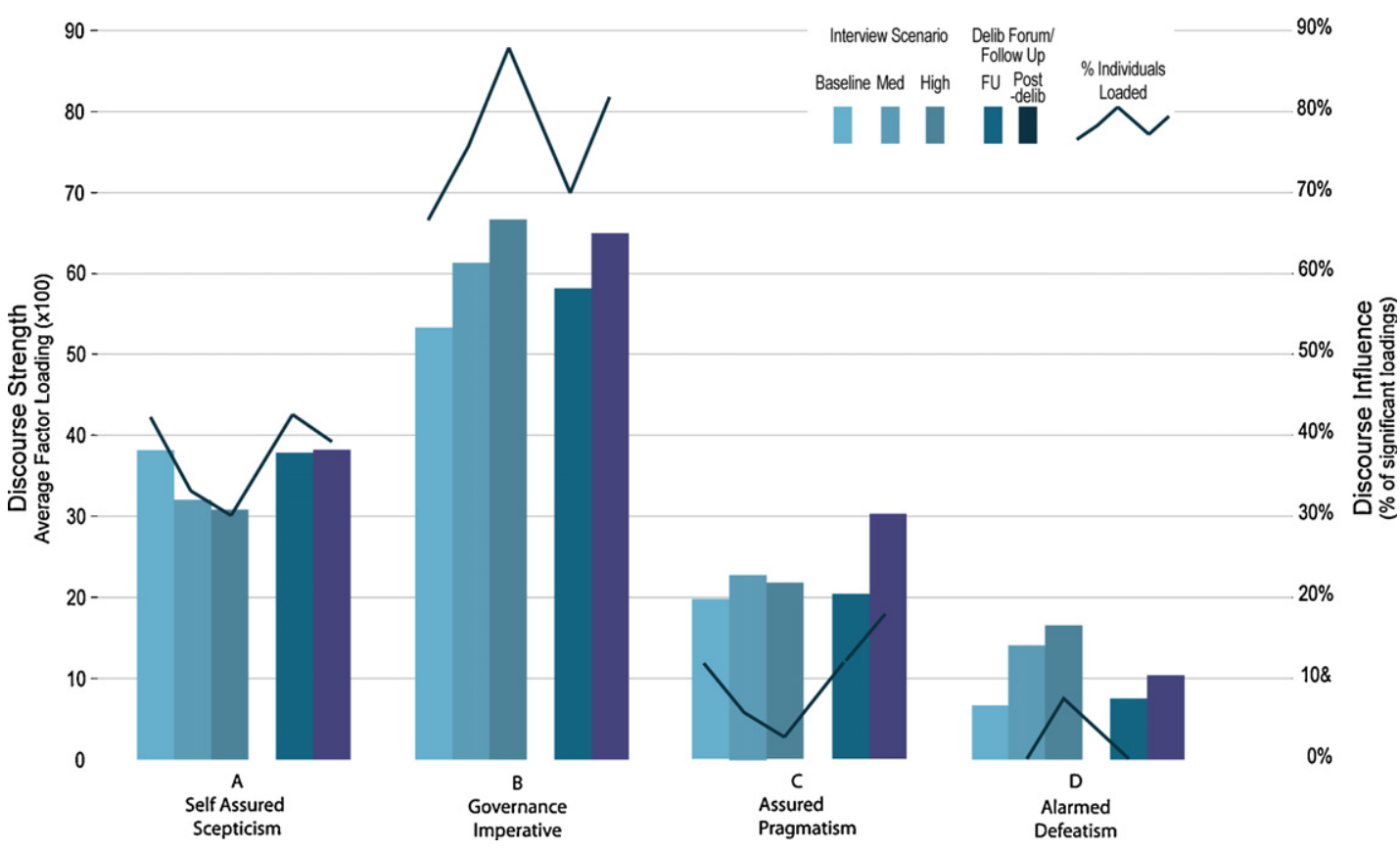

Fig. 4. Levels of association with scenario interview discourses.

\subsection{The impact of climate change interview scenarios on discourses}

Fig. 4 shows the overall level of influence of each of the above discourses amongst interview participants. It shows the average factor loading, which measures the level of agreement, and correlation between individual Q-sorts and the discourses at each of the study stages. The lines in the graph also plot the number of individuals who significantly agree with that discourse. ${ }^{3}$

From Fig. 4 it can be seen that the influence of discourses A and $C$ decrease compared to the Baseline, as the severity of the climate change scenarios increase, shown in the first three bars for each discourse. Discourses B and D, by contrast, increase in influence.

Fig. 5 shows the migrations of individual participants across the discourses between the Baseline and High emissions scenario during Phase 2 interviews. The arrows plot movement between the Baseline and High scenario positions of individuals (the stronger an individual is uniquely associated with a discourse, the further towards the corners they are positioned). Where an individual is associated with one or more discourses they are located in the overlap. An individual who is not associated with any discourse is shown outside the figure near the discourse they are most closely associated with. Those deeply sceptical about climate change are shown by the hashed arrows and are strongly negatively associated with B, D or both; and weakly associated with A.

Overall the above figures show that climate change scepticism decreased through the scenario interviews, dramatically so in some cases. Most of the movement between the baseline and high scenario is in a southeast direction from discourse A towards D. Those individuals who begin strongly loaded on B tend to stay there.

In $B$ and $D$ discourses for the High emissions scenario-and, to a lesser extent Medium-there is a strong increase in belief that we need to act and act now. As discussed below, there is a good deal of potential for a strongly maladaptive public response in both discourses: particularly in discourse $D$, which represents a withdrawal from collective attempts to deal with climate change.

\footnotetext{
${ }^{3}$ The level of significance was set at a correlation of 0.44 , corresponding to a $99 \%$ confidence level, where the standard error is calculated using $S E=1 / \sqrt{n}$, where $n=33$ is the number of statements used in the Q-sort.
}

Discourse B is less problematic, but does embody a difficult situation from a governance point of view as there is a strong demand for definitive action from government, while at the same time the low levels of trust in government.

Do the scenario interviews have a lasting effect on participants? To test this, 20 follow-up interviews were performed, showing very little change compared to the Baseline-indicated by second last bar in the graph shown in Fig. 4. That this happened in an intriguing comment on the mostly unsustained impact of climate scenarios: discussed in more detail elsewhere (see Hobson and Niemeyer, submitted).

\section{The impact of deliberation on climate adaptation discourses}

What difference then does deliberation makes to the above discourses, in terms of potential to improve adaptive capacity? In Fig. 4 above, the final bar for each discourse shows their respective strengths following the deliberative forum. It shows an increase in discourse B (though not to the same level as seen for the High scenario) and a relatively sharp increase in discourse C.

What Fig. 4 does not show is that these movements reflect a strong increase in consensus amongst the deliberative participants as is often the case with group deliberation (Niemeyer, 2011). ${ }^{4}$ Fig. 6 shows that this increased consensus results from a convergence of most participants around discourse $B$; the intersection between $\mathrm{B}$ and $\mathrm{C}$; or the intersection between $\mathrm{B}$ and $A$. Discourse $C$ has ostensibly increased, but a closer inspection of all associated participants reveals that, while they conform to many features associated with $\mathrm{C}$, they do not agree with its standout feature, i.e. the belief in the ability of technology to address adaptation issues. The smaller number of arrows in the figure compared to Fig. 5 is due to the smaller number of participants completing the deliberative process, compared to the scenario interviews.

However, further analysis reveals that the above discourses do not describe well the post-deliberative situation. Indeed, delibera-

\footnotetext{
${ }^{4}$ The average (Pearson) correlation between the $\mathrm{Q}$ sorts of deliberative participants increased from 0.48 to 0.60 between the baseline and post-deliberative stages.
} 


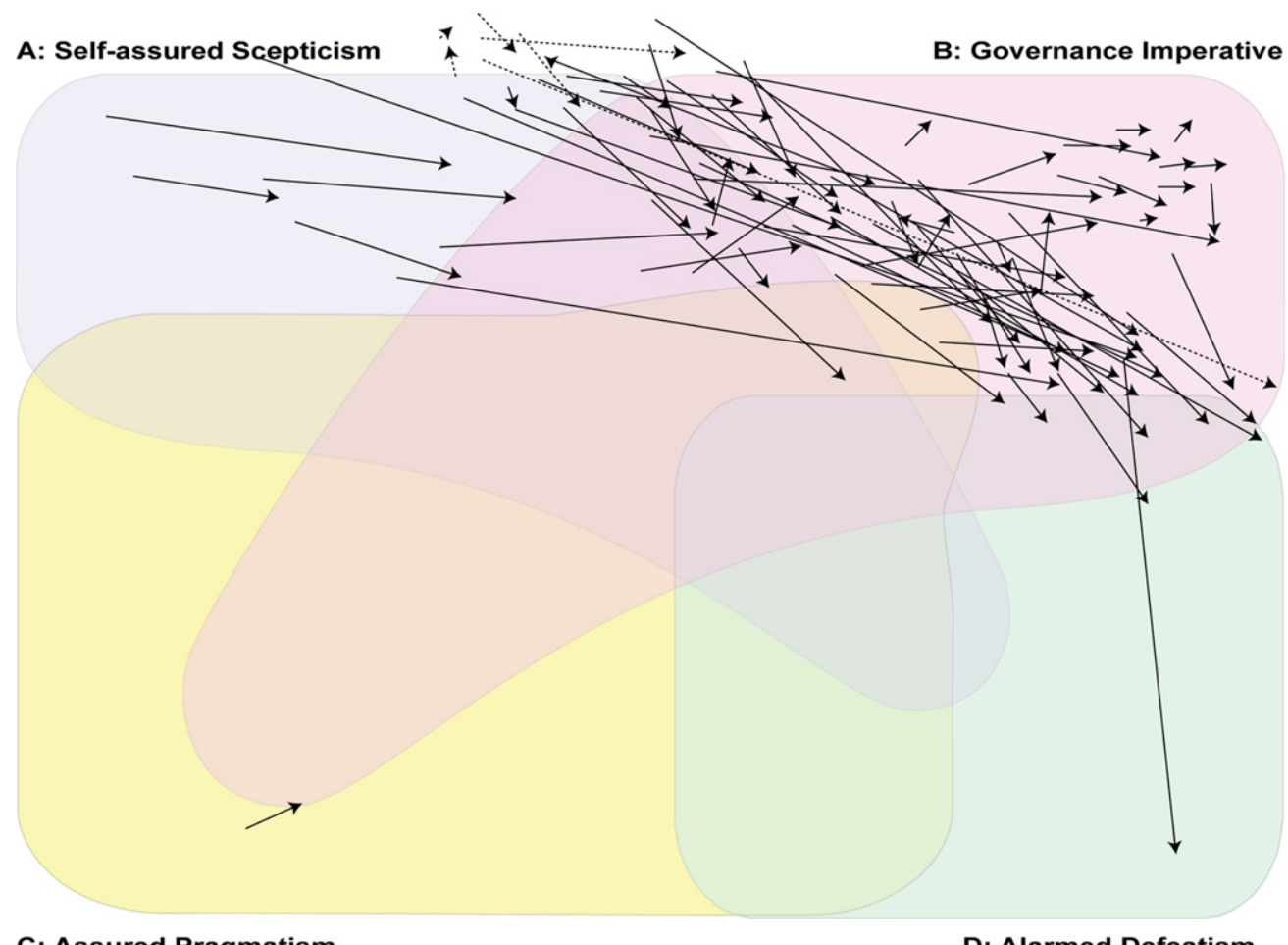

Fig. 5. Interview discourse migration: schematic representation of changes to participants' discourse association between the Baseline and High emissions scenario.

tion appeared to change the discursive landscape as part of an increased overall consensus. Thus, a second analysis was conducted using only the post deliberative $\mathrm{Q}$ sorts, which resulted in four new discourses. Two of these $\left(A^{\prime}\right.$ and $\left.B^{\prime}\right)$ are closely relatedbut different in important ways-to discourses A and B from the first analysis. The second two (E and F) are entirely new discourses that arose out of the deliberative process.

The new post-deliberative discourses are schematically described in Fig. 7 in the same manner as the scenario discourses in Fig. 3 (see Appendix A for factor scores). These new discourses are labelled as:

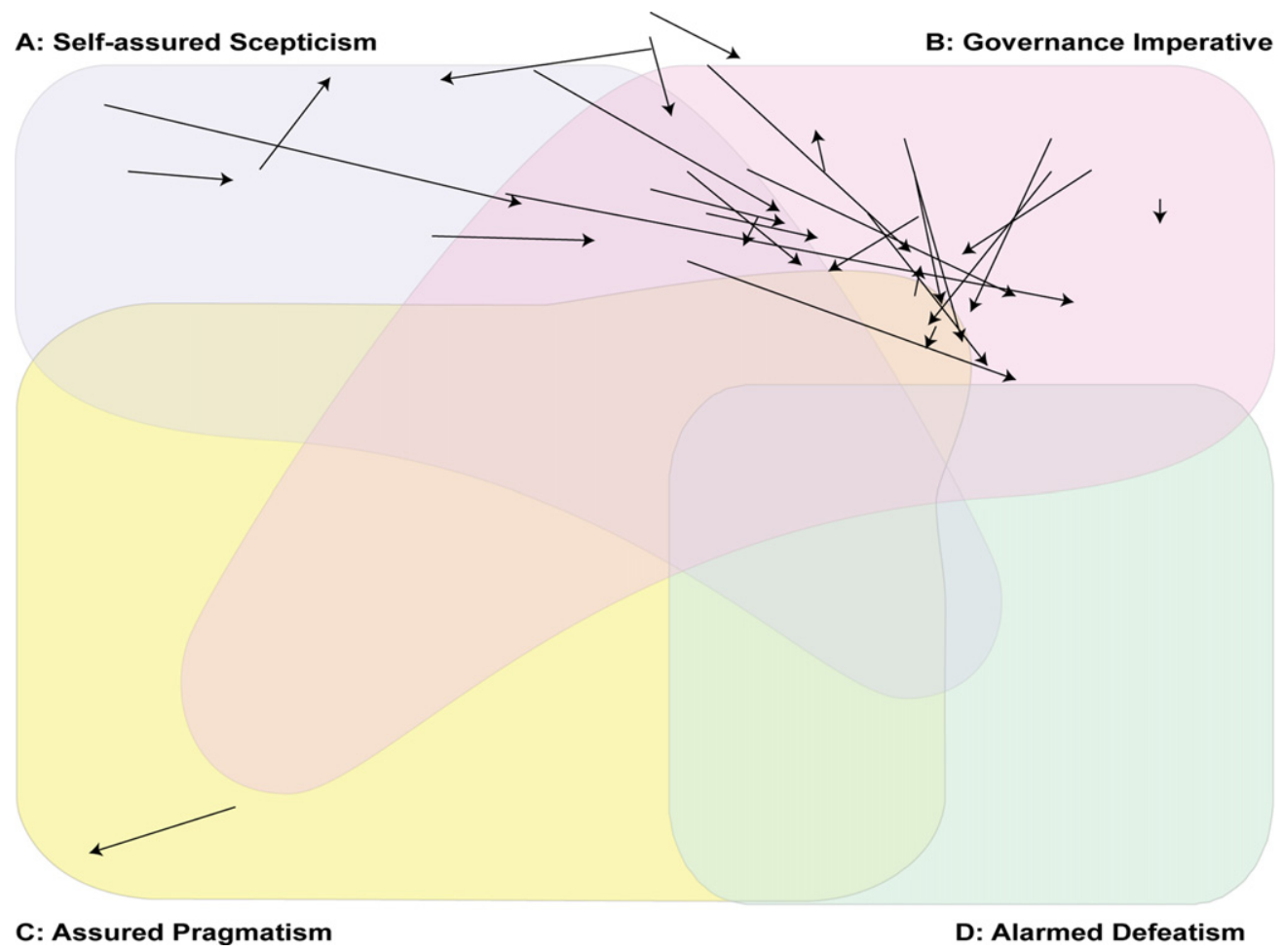

Fig. 6. Discourse migration: schematic representation of changes to participants' discourse association between the Baseline scenario and post-deliberation. 


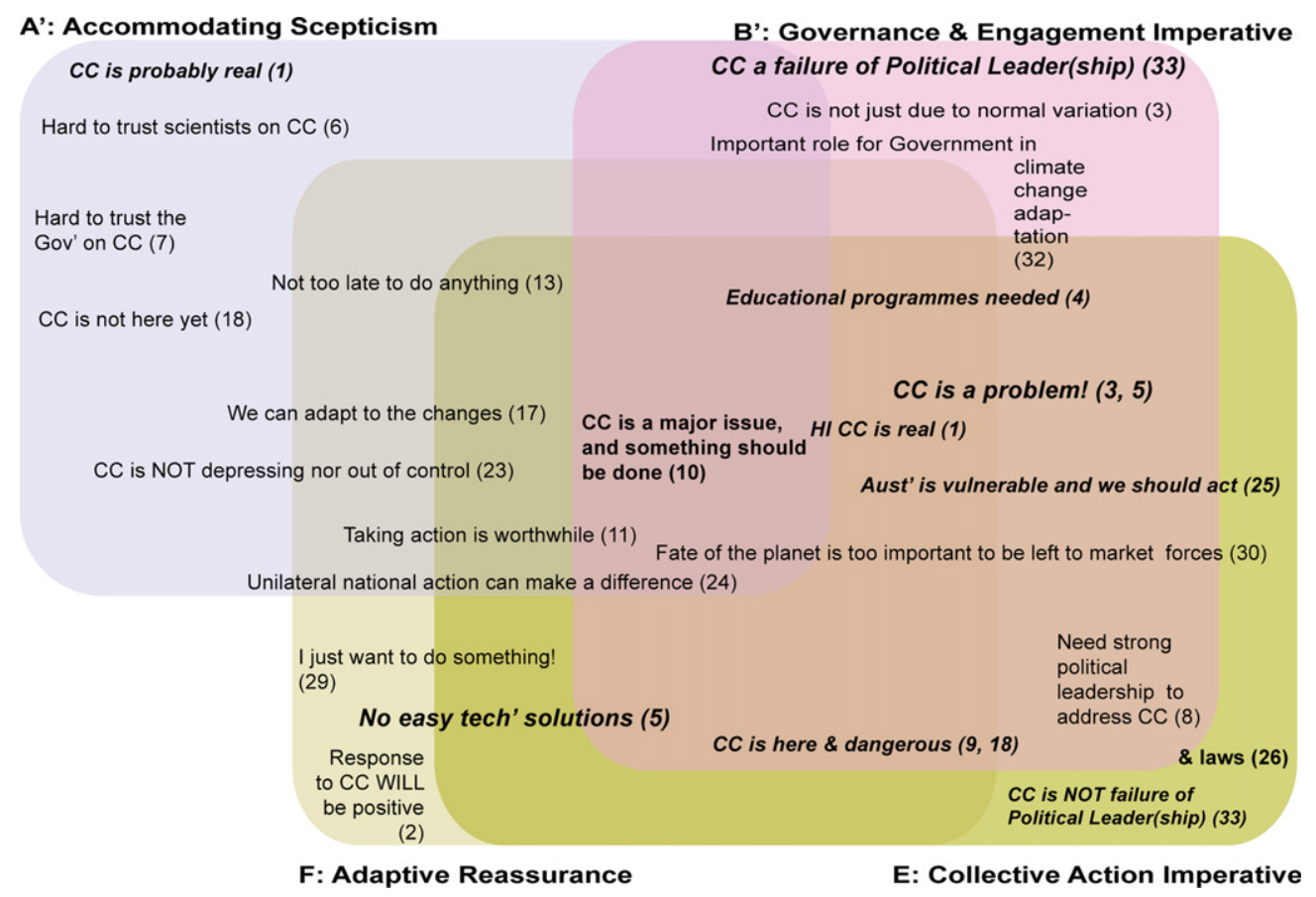

Fig. 7. Climate change discourses: post-deliberation.

A' Accommodating Scepticism

$B^{\prime}$ Governance and Engagement Imperative

E Collective Action Imperative

F Adaptive Reassurance

The increased overlap in Fig. 7 reflects the much closer relationship between the four discourses than was previously the case, in turn reflecting the increased consensus amongst the participants.

\subsection{Discourse $A^{\prime}$ : Accommodating Scepticism}

Discourse $A^{\prime}$ is similar to the original $A$ except it is more accommodating, e.g. increased willingness to engage with a wider variety of climate change policies and practices such as paying for greenhouse emissions. There was more optimism that personal actions are worthwhile and can make a difference; and less belief that they can be swayed by comments in the media that cast doubt on climate change. These findings suggest that the meta-cognitive confidence (Scannell and Grouzet, 2010) noted above in relation to discourse A may have been strengthened through taking part in deliberation, but that Meta-Cognitive Certainty (i.e. judgements about the likelihood of a given climate outcome) may have been weakened somewhat, enabling participants to engage more with the possibility that action may be necessary.

\subsection{Discourse $B^{\prime}$ : Government and Engagement Imperative}

Discourse $\mathrm{B}^{\prime}$ is largely similar to the original $\mathrm{B}$, but adopts a much stronger 'soft governance' (Brandsen et al., 2006) position, favouring engagement and education. The original stance against the use of market forces is softened suggesting recognition that a broad 'response space' (Brandsen et al., 2006) is indeed required. However, $\mathrm{B}^{\prime}$ is slightly less optimistic than $\mathrm{B}$. There is an increase in the belief of the futility of personal action and that it may already be too late to stop climate change. There is also less trust in the media, with comments during deliberation about its biased nature and lack of interest in 'good news' stories. As one participant put it:
"I'm a reasonably informed person, and I didn't know a fraction of the stuff I've learned in the last few days. So the media I think have got a lot to answer for. Apart from the lack of leadership from the government, even if they did have a message, it's not going to come through, because the media is obsessed with drama and conflict, and they don't seem to have the integrity just to tell the story. And this is the biggest story that's happening. And all of it's open to doubt, that people have expressed even here, and the media takes that doubt all out of proportion, so you don't realise that the science is as firm as it is" (Male, early 60s)

Primarily, discourse $B^{\prime}$ focuses on forms of community engagement and leadership. For example, one deliberative participant talked about attempts to create community leaders amongst the Australian indigenous community, as a possible template for garnering grass roots action on climate change. Amongst talk of 'bringing others along', there was also a strong acknowledgement of the need to not utilise fear and negative framings to motivate engagement with climate change: a point well made in the literature to date (Moser, 2010; O'Neill and Nicholson-Cole, 2009). As one participant put it:

"Is there a tension between the need to raise public concern to get action about climate change and the affect of this social and psychological stress on individuals? So I see it as a tension ... we've got to make people aware, so you tell them all the doom and gloom stuff. But then there are issues of stress levels in individuals, it affects their health because they're overwhelmed". (Female, late 60s)

In addition, there was an expressed concern here about how one can communicate climate change without vested interests confusing the issue, with one participant commenting that we need to 'think about ways to talk about the climate change without the politics interfering and clouding it all' (Female, mid 40s). 


\subsection{Discourse E: Collective Action Imperative}

Although discourse $\mathrm{E}$ is not the strongest of the four discourses following deliberation, it best represents the areas of consensus amongst deliberative forum participants. It shares with $\mathrm{A}^{\prime}$ optimism that it is not too late to do anything and that we can adapt. It also shares with $\mathrm{B}^{\prime}$ (and F) the belief that anthropogenic climate change is a real and serious issue that needs to be confronted. In contrast to $\mathrm{B}^{\prime}$, discourse $\mathrm{E}$ favours more traditional forms of governance via the instruments of the law.

What is different from $\mathrm{B}^{\prime}$ is the presence of optimism about our ability to adapt to coming changes, with a lesser tendency towards feeling that the issue is out of control and that individuals can make a difference. However, unlike $\mathrm{B}^{\prime}$ (and B), discourse $\mathrm{E}$ expressed a good deal of optimism about the prospects for adaptation in the face of much stronger perception about the reality of climate change. But this optimism does not translate into apathy or some sort of blind hope that humans can muddle through. Discourse E is about action. It represents a position not stymied by many of the barriers to action identified elsewhere (Lorenzoni et al., 2007), including personal willingness to alter lifestyles. This a sentiment echoes Wolf et al.'s (2009) 'Communitarian' discourse, i.e. being a responsible citizen and acting now, while viewing climate change as one symptom of a bigger problem. As one participant put it:

"I want to go mitigation all the way, and if that means that I can't get my new car or whatever the consequence is to help the future of the planet, if I don't just think about it as Canberra, I'm talking about the whole planet, I will do it. And I totally believe in a democracy, or a government. That's who creates this world, and who gives the laws, so as a citizen of the planet, I have to agree what the politician, or try to go with what the politician says."

This quote suggests a form of cosmopolitan environmental ethic (Barry, 2005) that links citizenship to justice, i.e. the need to move beyond self-interest to the common good (Dobson, 2003). From this perspective, it is not just down to laws and politicians to lead the way, but is a collective and other-focussed endeavour that has fairness amongst humans and also fairness to 'the planet' at its core.

\subsection{Discourse F: Adaptive Reassurance}

The ability to, and hope for, adaptation became a key theme for those associated with discourse F. It was expressed as a generalised idea that encompassed the (quite possibly wishful) thinking that, through some non-specific forms of adaptation, future generations will be able to cope. As one deliberative participant commented:

"It still concerns me that our children and grandchildren are going to move into this and we have no idea of what they're going to be facing and that's saddening for me. [Pause] But, I imagine that in some ways our children will only know this and so the hope is that they will grow up with it and they'll have the ideas anyway. They'll adapt more readily because this is all they have known, so this what we left them with and this is how they're going to deal with it." (Female, mid-40s)

Such statements can be interpreted as a form of denial, or at least a coping mechanism to deal with the discomfort that this participant feels on leaving a negative inheritance for her progeny (Norgaard, 2006).

More specifically, the idea was floated that only particular types of people would be able to adapt successfully. For example, one participant noted that:
"For those people who have not lived through years of drought and bushfires, they may not know what to do. We (Australians) adapt, but I don't think we should expect everyone to be able to, as they don't know a thing about it." (Female, 60s, follow-up interview)

This comment was made in the context of a conversation about the intrinsic toughness of Australian rural people and their ability to cope in the face of adversity. It suggests that cultural icons, such as the 'Aussie battler's evoked here-and their links to self-identityare an important component of responses to climate change (Smith et al., 2007): an issue the $Q$ statements could not measure but would make interesting further research around response to climate change in various socio-political and cultural contexts.

\section{Implications of post-deliberative discourses for adaptive capacity}

These four new discourses crystallised during the process of deliberation, illustrated in Fig. 8, which shows the levels of association attributable to them at all the stages of the study. All four discourses experience a significant increase in association following deliberation. Thus, deliberation does change individual positions regarding climate change: that is, there is less scepticism, more desire for action, and a greater willingness to act. It also alters the nature of the collective debate, as more people move closer together in terms of their position within the discourses.

What then does this imply about the impact deliberation can have on fostering public adaptive capacity? To return to the 5 questions posed in Section 2 of this paper-around recognition, knowledge, motivation, and personal and political efficacy-some can be explored through qualitative data gathered during this research. For example, in terms of increased information and knowledge, positive evidence exists. While this research did not test factual climate change knowledge amongst participants (see Sterman and Sweeney, 2007) some participants self-reported they had learnt a lot and felt more able to formulate coherent positions on the issues discussed, having been exposed to different attitudes and ideas for action. For example, one participant reflected that:

"I know a lot more, a hell of a lot more, and I don't feel anywhere near as threatened as before. I don't. Because I think it's achievable. It just means we put a few things on hold, get our priorities right, and look after this, otherwise it will be too late." (Male, mate 40s)

In the same session, another participant was also positive about the impact that the deliberative process had on her.

"I must congratulate everybody, because I think we've all moved. I mean, I must speak just for myself, but I feel I have moved a great distance since that interview. Because I'd reached a plateau, given the source of my disappointments. So I felt stymied. I don't feel stymied now, I don't feel threatened, I think I have hope, I have optimism. And I believe too I've changed." (Female, late 60s)

Beyond these self-reported changes, the above discourse descriptions can be examined in relation to the 5 adaptive capacity questions outlined in Section 2. Table 4 thus summarises

\footnotetext{
${ }^{5}$ The term 'Aussie Battler' has its roots deep in Australian folklore. Coming into common use around the 1890 s, it stands for an 'Individual who, despite having few material advantages, struggles against overwhelming odds with stoic humour ... In more recent times the concept has become a powerful icon of popular nationalism in the phrase 'the little Aussie battler' (Davey and Seal, 2003: 31).
} 


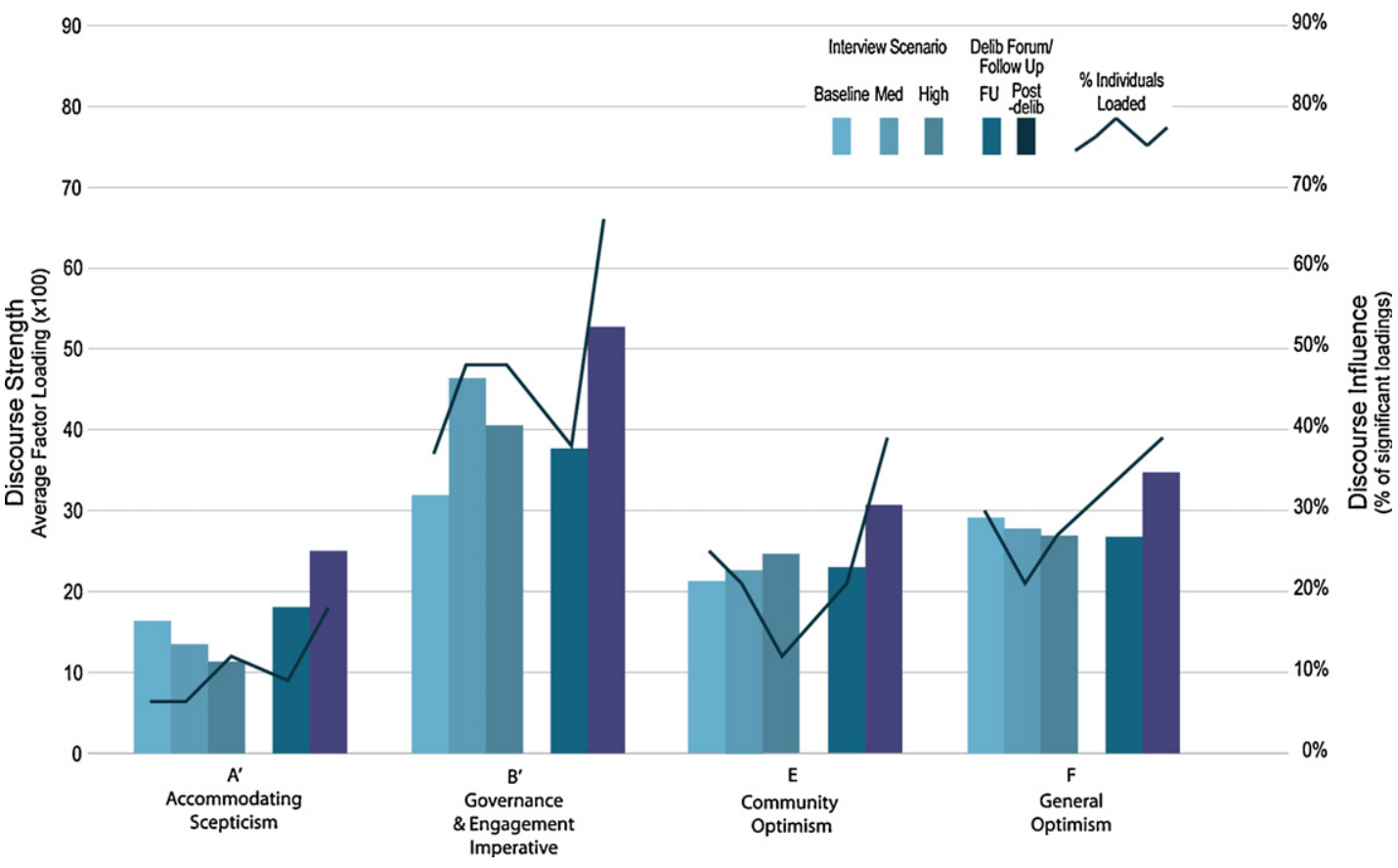

Fig. 8. Levels of association with post-deliberative discourses.

these adaptive capacity determinants and their relationships to both the end-of-interview discourse (A-D) and the post-deliberative discourses $\left(A^{\prime}-F\right)$. It presents an overall evaluation of the levels of adaptive capacity each discourse suggests. However, as Q method measures adherence to particular statements that can stand as proxies for adaptive capacity determinants (e.g. motivation, trust in political institutions) but are not actual quantitative measures of these determinants that can be tracked over time, the evaluations presented in Table 4 are provisional and open to debate: which, given the dearth of literature around adaptive capacity and deliberation is a debate this paper aims to stimulate further. For the sake of consistency however, a evaluative criteria was created wherein 'Low' adaptive capacity is given to discourses that are negative on all 5 determinants, and/or where any changes during the scenario interviews and/or deliberation remained so: 'Medium' for discourses that were positive on at least 2-4 determinants and where some positive changes had taken place: and finally 'High' was given to any discourses that were positive on all the 5 determinants and remained (or become more) so after either the interviews and/or deliberation.

Thus Table 4 suggests some discourses do appear to contain greater potential adaptive capacity than others. For example, out of the interview discourses only B seems to have potential in terms of responding positively to new knowledge about climate change. For the post-deliberative discourses, individuals loaded on $\mathrm{A}^{\prime}$ became more willing to consider a broader suites of policy options and personal input. However, they remain sceptical about some aspects of climate change; became more sceptical about climate modelling; and had low levels of trust towards key governance actors. Thus, although there has been a move away from strong scepticism, $A^{\prime}$ suggests that there exists low levels of support for challenging and/or controversial climate change policies.

Discourse $\mathrm{B}^{\prime}$ had the greatest number of participants loaded on it, and is positive in terms of recognising the need for a broad 'response space' (Table 4) in governing climate change. However, there were some potentially problematic elements, in terms of fostering adaptive capacity. For example, negative assessments of the governance status quo increased through deliberation, suggesting an erosion of aspects of political capital, which includes trust in public officials and current governance systems (Booth and Richard, 1998). At the same time, there was an increased focus on fostering social capital through widespread public engagement. However, discussion here centred on 'other people' taking the lead, rather than an emphasis on personal involvement and leadership. This is a reasonable stance, given that 'bottom up' change needs institutional support (see Folke et al., 2005). However, this is all taking place in a national context that has seen moderate climate change policy initiatives fail ${ }^{6}$; weak national emissions reduction targets set ${ }^{7}$; and environmental policies severely downgraded as an over-all national political priority (ABC News, 2011). Indeed, the need for 'unified elites' to take the lead in Australia climate change has been noted (Tranter, 2011), suggesting it remains a key but currently lacking facet of collective responses to climate change in Australia. Indeed, the corrosive effects of this political context can be seen in the following quote from one deliberative participant. Reflecting on how he feels, six months after participating in the forum, he comments that:

"I was more optimistic 6 months ago as I thought things were starting to change but nothing seems to be changing. As if this carries on for 5-10 years and the temperature changes as they predict then we're really going to have a problem." (Male, mid 40s)

Indeed, when some deliberative participants met in December 2010 for an informal feedback session on the research results from

\footnotetext{
${ }^{6}$ For example, a 'Carbon Pollution Reduction Scheme' White Paper was published in 2008, laying out targets for 2020. An Emissions Trading Scheme bill followed, introduced to the Federal parliament in 2009. The bill was rejected by $42-30$ votes in the Senate (see Tranter, 2011). In response, the Labor government said it would not introduce an ETS until 2013 and then, only if there is strong international movement on this front. This issue at the time received a great deal of media attention, as in response, the Opposition called for a double dissolution election.

7 The current Australian Labor government has stated that it does not intend to set national targets above $5 \%$ emissions cut by 2020 unless 'the level of global ambition becomes sufficiently clear' and 'the credibility of those commitments and actions is established' (Department of Climate Change and Energy Efficiency, 2010: no page), showing a 'wait and see' approach.
} 
Table 4

Determinants of adaptive capacity and their relationship to interview (A-D) and post-deliberative $\left(\mathrm{A}^{\prime}-\mathrm{F}\right)$ discourses.

\begin{tabular}{|c|c|c|c|c|c|c|c|c|}
\hline $\begin{array}{l}\text { Adaptive } \\
\text { capacity } \\
\text { determinants }\end{array}$ & $\begin{array}{l}\text { A: Self-Assured } \\
\text { scepticism }\end{array}$ & $\begin{array}{l}\text { B: Governance } \\
\text { Imperative }\end{array}$ & $\begin{array}{l}\text { C: Assured } \\
\text { Pragmatism }\end{array}$ & $\begin{array}{l}\text { D: Alarmed } \\
\text { Defeatism }\end{array}$ & $\begin{array}{l}\mathrm{A}^{\prime} \text { : Accommodating } \\
\text { Scepticism }\end{array}$ & $\begin{array}{l}\mathrm{B}^{\prime} \text { : Governance } \\
\text { and Engagement } \\
\text { Imperative }\end{array}$ & $\begin{array}{l}\text { E: Collective } \\
\text { Action } \\
\text { Imperative }\end{array}$ & $\begin{array}{l}\text { F: Adaptive } \\
\text { Reassurance }\end{array}$ \\
\hline 1. Recognition & Very little & $\begin{array}{l}\text { Yes: is an } \\
\text { major issue }\end{array}$ & $\begin{array}{l}\text { Some: but } \\
\text { not overly } \\
\text { concerned }\end{array}$ & $\begin{array}{l}\text { Strong } \\
\text { recognition: } \\
\text { despondency }\end{array}$ & $\begin{array}{l}\text { Yes: will } \\
\text { consider a } \\
\text { wider range } \\
\text { of policies }\end{array}$ & $\begin{array}{l}\text { Yes: need for } \\
\text { governance } \\
\text { strengthened }\end{array}$ & $\begin{array}{l}\text { Yes: need to } \\
\text { both mitigate } \\
\text { and adapt }\end{array}$ & $\begin{array}{l}\text { Yes, but very } \\
\text { generalised }\end{array}$ \\
\hline 2. Knowledge & $\begin{array}{l}\text { Some: but } \\
\text { viewed } \\
\text { through } \\
\text { sceptical } \\
\text { lens }\end{array}$ & $\begin{array}{l}\text { Yes: has } \\
\text { heightened } \\
\text { need to } \\
\text { take action }\end{array}$ & $\begin{array}{l}\text { Little: but } \\
\text { climate change } \\
\text { is not a } \\
\text { major issue }\end{array}$ & $\begin{array}{l}\text { Yes: confirms } \\
\text { current belief } \\
\text { systems }\end{array}$ & $\begin{array}{l}\text { Some: climate } \\
\text { change as } \\
\text { anthropogenic } \\
\text { and potentially } \\
\text { problematic }\end{array}$ & $\begin{array}{l}\text { Yes: heightened } \\
\text { sense of urgency }\end{array}$ & $\begin{array}{l}\text { Yes: sense of } \\
\text { both urgency } \\
\text { and collective } \\
\text { danger increased }\end{array}$ & $\begin{array}{l}\text { Yes: optimistic } \\
\text { about a } \\
\text { bility to adapt }\end{array}$ \\
\hline 3. Motivation & Very little & $\begin{array}{l}\text { Little: focus } \\
\text { on political } \\
\text { inaction }\end{array}$ & $\begin{array}{l}\text { In a abstract } \\
\text { sense: little } \\
\text { commitment }\end{array}$ & $\begin{array}{l}\text { Not in the face } \\
\text { of social collapse }\end{array}$ & $\begin{array}{l}\text { Slight: will take } \\
\text { personal action } \\
\text { but little strong } \\
\text { commitment }\end{array}$ & $\begin{array}{l}\text { Focussed on } \\
\text { others but } \\
\text { willing } \\
\text { to take part }\end{array}$ & $\begin{array}{l}\text { Yes: willingness } \\
\text { to 'go without' }\end{array}$ & $\begin{array}{l}\text { Not clear: } \\
\text { relying on } \\
\text { adaptation }\end{array}$ \\
\hline $\begin{array}{l}\text { 4. Personal } \\
\text { Efficacy }\end{array}$ & Not relevant & Low, due to 3 . & $\begin{array}{l}\text { Low: cynical } \\
\text { about action }\end{array}$ & Irrelevant & Slight & $\begin{array}{l}\text { Low: not } \\
\text { optimistic }\end{array}$ & $\begin{array}{l}\text { High: 'we can } \\
\text { do it' }\end{array}$ & $\begin{array}{l}\text { Slight and } \\
\text { general }\end{array}$ \\
\hline $\begin{array}{l}\text { 3. Political } \\
\text { Efficacy }\end{array}$ & $\begin{array}{l}\text { High levels of } \\
\text { distrust in the } \\
\text { experts and } \\
\text { institutions }\end{array}$ & $\begin{array}{l}\text { Need leadership } \\
\text { but it is not } \\
\text { forthcoming }\end{array}$ & $\begin{array}{l}\text { Technology } \\
\text { will sort it out }\end{array}$ & $\begin{array}{l}\text { Becomes } \\
\text { meaningless } \\
\text { as society } \\
\text { collapses }\end{array}$ & $\begin{array}{l}\text { Still distrustful } \\
\text { of institutions; } \\
\text { increased } \\
\text { scepticism of } \\
\text { modelling }\end{array}$ & $\begin{array}{l}\text { Focus on } \\
\text { engagement: } \\
\text { dissatisfaction } \\
\text { with the } \\
\text { status quo }\end{array}$ & $\begin{array}{l}\text { Environment-al } \\
\text { citizenship: } \\
\text { everyone } \\
\text { doing their bit }\end{array}$ & $\begin{array}{l}\text { Government } \\
\text { to take the } \\
\text { lead: citizens } \\
\text { will adapt } \\
\text { somehow }\end{array}$ \\
\hline $\begin{array}{l}\text { Overall } \\
\text { evaluation }\end{array}$ & Low & Medium & Low & Low & Low & Medium & High & Medium \\
\hline
\end{tabular}

this project-during which they were shown where they were positioned in the discourses-one participant commented:

"I am in the 'government imperative' [discourse] but if you look at it realistically, that is not going to happen. The people are not in control: it is business. It is market forces: that's what's dictating the terms." (Male, mid-60s)

This reflected the potential already noted in the high scenario movement from B to D to despair about, and withdraw from, efforts to deal with a changing climate. However, there is some cause for optimism about the potential of deliberation fostering adaptive capacity. It is argued that, of all the discourses discussed in this paper, the post-deliberative discourse E (Collective Action Imperative) has the most potential. Here, the focus on strong political leadership is matched by a willingness to make personal changes to lifestyles and attitudes, echoing the flexible and selforganised forms of association that the adaptive capacity literature suggests as desirable (e.g. see Folke et al., 2005; Kalikoski et al., 2010). Thus, overall, the aim is to lessen the occurrence and impacts of climate change, not just for personal benefit, but for the 'whole world', as one participant put it.

\section{Concluding comments}

This paper began by questioning the difference that deliberating about climate change can make to fostering aspects of adaptive capacity. Through exploring and interweaving quantitative analysis (i.e. data from multiple $Q$ sorts in research Phases 2 and 3 ) and qualitative data (drawn from the interviews, deliberative forum, and follow-up meetings) it argues that deliberation does have an impact on individuals' perceptions on climate change. Several sceptical participants became less so: a trend that did not appear so strongly for those who took part in the interviews only. And the position that the government and the government alone needed to take the lead and act became softened somewhat, with other actors and governance mechanisms being considered viable and desirable. This latter change arguably opens up the 'response space', wherein participants might now be more inclined to accept a broad range of policy initiatives on climate change, beyond the narrowly defined debate in Australia in the years leading up to the deliberative process, which focussed on emissions trading and the 'failure' of the United Nations 2009 Conference in Copenhagen.

But there is every reason to be cautious about these results. For one, the two case studies discussed here would benefit from further examples, drawn from across Australia and globally to enable the teasing out of the impact of geographical and cultural contexts in discourse changes. Also, there are methodological issues that require further research. For example, in this paper, the discourses mapped out are taken as partially indicative of the prevailing worldviews of research participants. However, this does not suggest any firm conclusions can be drawn about future actions. Although discourses do formulate ones dispositions and therefore one's propensities to act, they can in no way be taken as firmly predictive of current or future behaviour, i.e. adaptive action. Plus, as the adaptive capacity literature shows, there are many other determinants at play, including how capacities are distributed within and across societies.

However, this research can offer some insight into issues around deliberation and governing climate change. As already noted the majority of participants were post-deliberatively clustered about $\mathrm{B}^{\prime}$ but not $\mathrm{E}$. However, one-third of participants were significantly (though not uniquely) loaded on E, with a general movement towards $\mathrm{F}$ throughout the deliberative process. This suggests that, perhaps given more time and space to learn, think and deliberate, more participants might have moved further towards the 'Collective Action Imperative' discourse. Yet, how realistic is it to suggest yet more time spent deliberating, for these particular individuals, and in general? This is not only a pragmatic question of research participants 'burning out', but an issue of deliberation being embedded in particular socio-political contexts and economies (see Hobson, 2009): particularly one that is not responding to the issue of climate change at the speed and in the direction research participants felt it should. Given the current lack of political leadership on climate change in Australia, that continues on past 'no regrets' trajectories (see Bulkeley, 2001), the optimism and feelings of collective understanding some 
deliberative participants feel once they 'leave the room' can give rise to greater despondency than before deliberation. Thus, definite caution has to be applied in taking broad statements about the merits of deliberation at face value, especially when the prevailing public discourse remains non-deliberative and distorted (Niemeyer, 2011).

Thus, further critical, inter-disciplinary and mixed methods research is needed to tease out the values of utilising deliberation as a key plank of building adaptive capacity. Without doubt deliberation does make a difference: more so, than just providing individuals with climate change information, as in the scenario interviews. But arguing that specific public deliberative platforms can offer an effective and efficient means of fostering broader adaptive capacity requires a more staid and agnostic response, as this research has shown.

\section{Acknowledgements}

This research was funded by the Australian Research Council, Discovery Grant DP0879092. Our gratitude is extended to the other researchers on this Grant: Will Steffen, Michael Hutchinson, Janette Lindesay, Brendan Mackey and Paul t'Hart. Thanks also to the project staff for all their hard work: Jacqui Russell, Imogen Ord-Evans, Elaine Santos, Juliana Dias, John Boswell and Sam McKeon, along with Kath Fisher for excellent facilitation, and all the staff who assisted with the interviews and other facets of the research. We are vastly indebted to all the research participants who gave up their time to share and debate their views and opinions: as well as the 3 anonymous reviewers for their constructive comments. All remaining errors are the sole responsibility of the authors.

Appendix A. Emissions scenarios timeline.

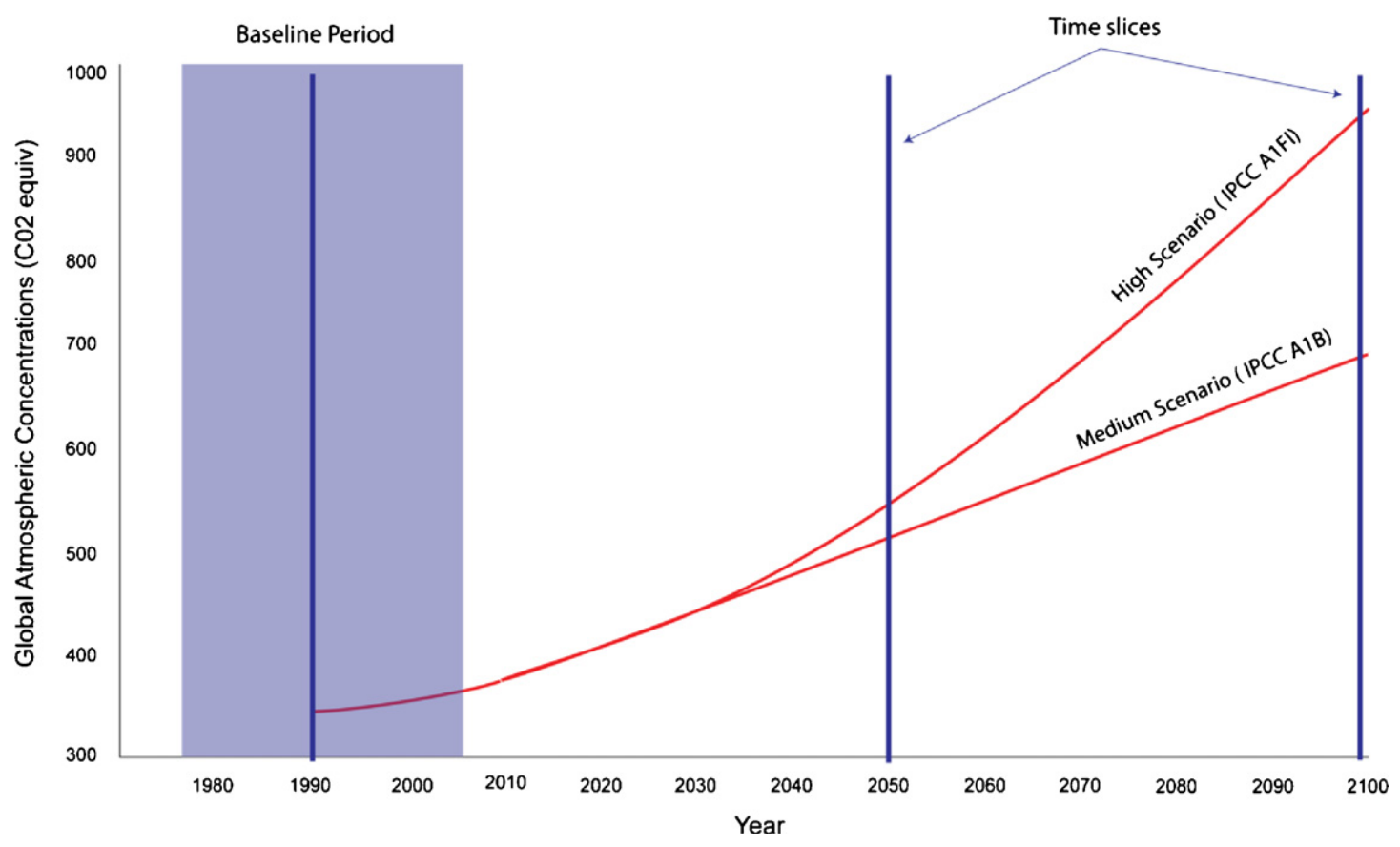

Appendix B. Factor scores: climate change governance discourses.

\begin{tabular}{|c|c|c|c|c|c|c|c|c|}
\hline \multirow[t]{3}{*}{ Statement } & \multicolumn{8}{|c|}{ Factor scores (discourses) } \\
\hline & \multicolumn{4}{|c|}{$\begin{array}{l}\text { First analysis } \\
\text { (all climate change } \\
\text { Q sorts) }\end{array}$} & \multicolumn{4}{|c|}{$\begin{array}{l}\text { Second analysis } \\
\text { (deliberative forum } \\
\text { participants only }\end{array}$} \\
\hline & A & B & $\mathrm{C}$ & $\mathrm{D}$ & $\mathrm{A}^{\prime}$ & $\mathrm{B}^{\prime}$ & $\mathrm{D}$ & $\mathrm{E}$ \\
\hline 1. There is not enough information to definitively say that climate change is real. & 1 & -5 & -5 & -5 & -2 & -5 & -3 & -1 \\
\hline 2. The response to climate change is not going to be positive. The same mistakes will keep happening. & -1 & 0 & -3 & -3 & 0 & -1 & -1 & -5 \\
\hline 3. Climate variation is normal, so why should this be a problem? & 0 & -3 & 0 & 0 & -1 & -3 & 0 & -1 \\
\hline 4. More educational programmes are needed to increase public awareness about climate change. & 4 & 2 & 2 & 3 & 3 & 5 & 2 & 1 \\
\hline 5. Climate change will not be a problem because there will be technological solutions available. & 0 & -1 & 5 & 0 & 1 & 0 & -2 & -3 \\
\hline 6. I don't trust what scientists say about climate change. & 1 & -4 & -5 & 2 & 1 & -5 & 0 & -1 \\
\hline 7. I don't trust what I hear about climate change from government. & 3 & 0 & -2 & 2 & 4 & 0 & 0 & 0 \\
\hline 8. We need strong political leadership to do something about climate change. & 1 & 5 & 4 & 4 & 2 & 5 & 3 & 1 \\
\hline 9. I think it is safe to say climate change is here. & 2 & 2 & 4 & -1 & 3 & 4 & 1 & 3 \\
\hline 10. I'm not going to do anything to address climate change because it is not a major issue. & -5 & -5 & -3 & -2 & -5 & -4 & -3 & -3 \\
\hline 11. There's not much point in me doing anything to fix this. No-one else is going to. & -5 & -2 & -1 & -1 & -5 & -2 & -4 & -4 \\
\hline 12. It's difficult to trust what comes out in the media on the issue of climate change. & 5 & 1 & 1 & -3 & 5 & 1 & 1 & 4 \\
\hline
\end{tabular}


Appendix B (Continued)

\begin{tabular}{|c|c|c|c|c|c|c|c|c|}
\hline \multirow[t]{3}{*}{ Statement } & \multicolumn{8}{|c|}{ Factor scores (discourses) } \\
\hline & \multicolumn{4}{|c|}{$\begin{array}{l}\text { First analysis } \\
\text { (all climate change } \\
\text { Q sorts) }\end{array}$} & \multicolumn{4}{|c|}{$\begin{array}{l}\text { Second analysis } \\
\text { (deliberative forum } \\
\text { participants only }\end{array}$} \\
\hline & A & B & $\mathrm{C}$ & $\mathrm{D}$ & $\mathrm{A}^{\prime}$ & $\mathrm{B}^{\prime}$ & $\mathrm{D}$ & E \\
\hline $\begin{array}{l}\text { 13. It is already too late to do anything, as any action to stop climate change will take a long time to take } \\
\text { effect. }\end{array}$ & -4 & -1 & 3 & -3 & -3 & -1 & -4 & -5 \\
\hline 14. I'm not concerned enough to do anything drastic about this, such as participate in political action. & -3 & -3 & -1 & 3 & -2 & -3 & -1 & -2 \\
\hline 15. It is unfair that we are going to leave the climate in a mess for future generations. & 4 & 3 & 2 & 1 & 4 & 3 & 2 & 5 \\
\hline 16. We should pay for greenhouse emissions. & -1 & 2 & 0 & 2 & 0 & 2 & 1 & 3 \\
\hline 17. We can adapt to the coming changes. & 3 & 0 & 5 & -2 & 2 & 0 & 2 & 3 \\
\hline 18. It is clear that we are already entering the zone of dangerous climate change. & -2 & 3 & 1 & 0 & -1 & 2 & 3 & 2 \\
\hline 19. I care about the planet. & 5 & 1 & 0 & 5 & 5 & 3 & 4 & 5 \\
\hline $\begin{array}{l}\text { 20. I don't know what to do. I'm very concerned and would like to do something, but I don't have a realistic } \\
\text { shortlist of things that would really make a difference. }\end{array}$ & -2 & 0 & 1 & 3 & -1 & 1 & -1 & -4 \\
\hline 21. Australia does not owe it to the rest of the world to reduce emissions and suffer economically. & 0 & -3 & -2 & 1 & 0 & -3 & 0 & -1 \\
\hline $\begin{array}{l}\text { 22. If Australia reduces greenhouse gases it won't make a difference. That will just shift Australian jobs to } \\
\text { other countries. }\end{array}$ & 0 & -2 & -3 & 1 & 0 & -1 & 0 & -2 \\
\hline 23. This is so depressing and is so out of our control. & -3 & 0 & -4 & -5 & -4 & 0 & -5 & 0 \\
\hline $\begin{array}{l}\text { 24. I believe that the difference we can have as an individual, in Australia, is so minimal that our actions are } \\
\text { worthless. }\end{array}$ & -4 & -1 & 3 & 0 & -4 & -2 & -5 & -3 \\
\hline $\begin{array}{l}\text { 25. Australia is particularly vulnerable to climate change, and it is in our interest to help find an effective } \\
\text { global solution. }\end{array}$ & 3 & 4 & 3 & 4 & 2 & 3 & 4 & 2 \\
\hline 26. We need laws addressing climate change because people are not going to volunteer to change. & -1 & 3 & -1 & 5 & 0 & 2 & 5 & 1 \\
\hline 27. I want to do something, but it is too big and too hard. & -3 & -1 & 1 & -4 & -3 & -1 & -1 & -2 \\
\hline $\begin{array}{l}\text { 28. When I read in the paper that climate change is not true, I start to have doubts about whether it is } \\
\text { changing. }\end{array}$ & -1 & -2 & -1 & -1 & -3 & -2 & -2 & 0 \\
\hline $\begin{array}{l}\text { 29. Doing something to reduce emissions feels a bit hopeless but I just want to feel that I'm doing the most I } \\
\text { can. }\end{array}$ & 2 & 1 & 0 & 0 & -2 & 0 & 1 & 4 \\
\hline 30. The fate of the planet is too important to be left to market forces. & 2 & 5 & 2 & -2 & 1 & 1 & 5 & 2 \\
\hline 31. Australia's emissions are tiny, so it's not up to us to act. & -2 & -4 & -4 & -1 & -1 & -4 & -3 & 0 \\
\hline $\begin{array}{l}\text { 32. Governments should take a far greater role in preparing towns and cities to adapt to the impacts of } \\
\text { climate change. }\end{array}$ & 1 & 4 & 0 & 1 & 3 & 4 & 3 & 1 \\
\hline 33. Failure to address climate change is the fault of political leaders. & 0 & 1 & -2 & -4 & 1 & 1 & -2 & 0 \\
\hline
\end{tabular}

\section{References}

ABC News, 2011. Government cuts to green programs. http://www.abc.net.au/ news/stories/2011/01/27/3123451.htm (accessed 04.02.11).

Adger, W.N., Arnell, N.A., Tompkins, E.L., 2005. Successful adaptation to climate change across scales. Global Environmental Change 1, 77-86.

Adger, W.N., Brown, K., Fairbrass, J., Jordan, A., Paavola, J., Rosendo, S., Seyfang, G. 2003. Governance for sustainability: towards a 'thick' analysis of environmental decisionmaking. Environment and Planning A 35, 1095-1110.

Adger, W.N., Dessai, S., Goulden, M., Hulme, M., Lorenzoni, I., Nelson, D.R., Naess, L.O., Wolf, J., Wreford, A., 2009. Are there social limits to adaptation to climate change? Climatic Change 93, 335-354.

Bankoff, G., 2001. Rendering the world unsafe: ‘vulnerability' as western discourse. Disasters 25, 19-35.

Barry, J., 2005. Resistance is fertile: from environmental to sustainability citizenship. In: Dobson, A., Bell, D. (Eds.), Environmental Citizenship. The MIT Press Cambridge, MA.

Barry, J., Proops, J., 1999. Seeking sustainability discourses with Q methodology. Ecological Economics 28, 337-346.

Berkhout, F., 2010. Reconstructing boundaries and reason in the climate debate. Global Environmental Change 20, 565-569.

Berkhout, F., Hertin, J., 2000. Socio-economic scenarios for climate impact assessment. Global Environmental Change 10, 165-168.

Booth, J.A., Richard, P.B., 1998. Civil society, political capital, and democratization in Central America. The Journal of Politics 60, 780-800.

Brandsen, T., Boogers, M., Tops, P., 2006. Soft governance, hard consequences: the ambiguous status of unofficial guidelines. Public Administration Review 66, 546-553.

Brooks, N., Neil Adger, W., Mick Kelly, P., 2005. The determinants of vulnerability and adaptive capacity at the national level and the implications for adaptation. Global Environmental Change Part A 15, 151-163.

Brown, S.R., 1980. Political Subjectivity: Applications of Q Methodology in Political Science. Yale University Press, New Haven.

Bulkeley, H., 2001. No regrets? Economy and environment in Australia's domestic climate change policy process. Global Environmental Change 11, 155-169.

Darier, E., 1999. Discourses of the Environment. Blackwell, Oxford.

Davey, G.B., Seal, G., 2003. A Guide to Australian Folklore. Kangaroo Press, Sydney. Department of Climate Change and Energy Efficiency, 2010. "National Targets" Australian Government. http://www.climatechange.gov.au/en/government/ reduce/national-targets.aspx (accessed 15.01.11).

Dobson, A., 2003. Citizenship and the Environment. Oxford University Press, Oxford.

Dryzek, J.S., 1993. Reconstructive democratic theory. American Political Science Review 87, 48-60.
Dryzek, J.S., 1994. Australian discourses of democracy. Australian Journal of Political Science 29, 221-239.

Dryzek, J.S., 1997. The Politics of the Earth: Environmental Discourses. Oxford University Press, Oxford; New York.

Dryzek, J.S., Niemeyer, S.J., 2008. Discursive representation. American Political Science Review 102, 481-494.

Eakin, H., Lemos, M.C., 2006. Adaptation and the state: Latin America and the challenge of capacity-building under globalization. Global Environmenta Change 16, 7-18.

Fazey, I., Fazey, J.A., Fischer, J., Sherren, K., Warren, J., Noss, R.F., Dovers, S.R., 2007 Adaptive capacity and learning to learn as leverage for social-ecological resilience. Frontiers in Ecology and the Environment 5, 375-380.

Few, R., Brown, K., Tompkins, E.L., 2007. Public participation and climate change adaptation: avoiding the illusion of inclusion. Climate Policy 7, 46-59.

Folke, C., Carpenter, S., Elmqvist, T., Gunderson, L., Holling, C.S., Walker, B., Bengtsson, J., Berkes, F., Colding, J., Danell, K., Falkenmark, M., Gordon, L., Kasperson, R. Kautsky, N., Kinzig, A., Levin, S., Mäer, K.-G., Moberg, F., Ohlsson, L., Olsson, P., Ostrom, E., Reid, W., Rockströ, J., Savenije, H., Svedin, U., 2002. Resilience and sustainable development: building adaptive capacity in a world of transformations. Scientific Background Paper on Resilience for the process of The World Summit on Sustainable Development on behalf of The Environmental Advisory Council to the Swedish Government, [online] URL: http://www.sou.gov.se/ $\mathrm{mvb} / \mathrm{pdf} /$ resiliens.pdf.

Folke, C., Hahn, T., Olsson, P., Norberg, J., 2005. Adaptive governance of socialecological systems. Annual Review of Environment and Resources 30, 441-473.

Gallopin, G.C., 2006. Linkages between vulnerability, resilience, and adaptive capacity. Global Environmental Change 16, 293-303.

Garnaut, R., 2008. The Garnaut Climate Change Review, Final Report. Cambridge University Press, Cambridge.

Hahn, T., Olsson, P., Folke, C., Johansson, K., 2006. Trust-building, knowledge generation and organizational innovations: the role of a bridging organization for adaptive comanagement of a Wetland Landscape around Kristianstad, Sweden. Human Ecology 34, 573-592.

Hajer, M., 1995. The Politics of Environmental Discourse: Ecological Modernization and the Policy Process. Clarendon Press, Oxford.

Hobson, K., 2009. On a governmentality analytics of the ‘deliberative turn': material conditions, rationalities and the deliberating subject. Space and Polity13,175-191.

Hobson, K., Niemeyer, S. What climate sceptics believe: discourse migration, scenarios, and deliberation in the Australian Capital Region. Public Understanding of Science, submitted.

IPCC, 2000. IPCC Special Report Emissions Scenarios-Summary for Policymakers, A Special Report of the IPCC Working Group III. In: Change, I.P.o.C. (Ed.). International Panel on Climate Change. 
Janicke, M., 2008. Ecological modernisation: new perspectives. Journal of Cleaner Production 16, 557-565.

Kalikoski, D.C., Netoa, P.Q., Almudi, T., 2010. Building adaptive capacity to climate variability: the case of artisanal fisheries in the estuary of the Patos Lagoon, Brazil. Marine Policy 34, 742-751.

Keskitalo, E.C.H., Dannevig, H., Hovelsrud, G.K., West, J.J., Swartling, A.G., 2010. Adaptive Capacity Determinants in Developed States: Examples from the Nordic Countries and Russia. Regional Environmental Change.

Lopez-Marrero, T., 2010. An integrative approach to study and promote natural hazards adaptive capacity: a case study of two flood-prone communities in Puerto Rico. The Geographical Journal 176, 150-163.

Lorenzoni, I., Leiserowitz, A., Doria, M.D.F., Poortinga, W., Pidgeon, N.F., 2006. Crossnational comparisons of image associations with "Global Warming" and "Climate Change" among laypeople in the United States of America and Great Britain. Journal of Risk Research 9, 265-281.

Lorenzoni, I., Nicholson-Cole, S., Whitmarsh, L., 2007. Barriers perceived to engaging with climate change among the UK public and their policy implications. Global Environmental Change 17, 445-459.

Milestad, R., Westberg, L., Geber, U., Björklund, J., 2010. Enhancing adaptive capacity in food systems: learning at farmers' markets in Sweden. Ecology and Society 15 Article no. 29.

Marx, S.M., Weber, E.U., Orlove, B.S., Leiserowitz, A., Krantz, D.H., Roncoli, C., Phillips, J., 2007. Communication and mental processes: experiential and analytic processing of uncertain climate information. Global Environmental Change 17, 47-58.

Morton, T.A., Rabinovich, A., Marshall, D., Bretschneider, P., 2011. The future that may (or may not) come: how framing changes responses to uncertainty in climate change communication. Global Environmental Change 2, 103-109.

Moser, S.C., 2010. Communicating climate change: history, challenges, process and future directions. WIREs Climate Change 1, 31-53.

Niemeyer, S.J., 2011. The emancipatory effect of deliberation: empirical lessons from mini-publics. Politics \& Society 39, 103-140.

Norgaard, K.M., 2006. "People want to protect themselves a Little Bit": emotions, denial and social movement nonparticipation. Sociological Inquiry 76, 372396.

O'Neill, S., Nicholson-Cole, S., 2009. “Fear Won't Do It": promoting positive engagement with climate change through visual and iconic representations. Science Communication 30, 355-379.

Ong, A., Zafiris, M., Govan, C., 2010. Community attitudes to climate change. National Climate Change Adaptation Research Facility-Australian Climate Change Adaptation Research Network for Settlements and Infrastructure Report.

Petts, J., 2007. Learning about learning: lessons from public engagement and deliberation on urban river restoration. The Geographical Journal 173, 300-311.
Posey, J., 2009. The determinants of vulnerability and adaptive capacity at the municipal level: evidence from floodplain management programs in the United States. Global Environmental Change 19, 482-493.

Risby, J., 2008. The new climate discourse: alarmist or alarming? Global Environmental Change 18, 26-37.

Scannell, L., Grouzet, F.M.E., 2010. The metacognitions of climate change. New Ideas in Psychology 28, 94-103.

Segnit, N., Ereaut, G., 2007. Warm Words II: How the Climate Story is Evolving and the Lessons we can Learn for Encouraging Public Action. Institute for Public Policy Research and the Energy Saving Trust http://www.ippr.org.uk/ publicationsandreports/publication.asp?id=561 (accessed 26.01.11).

Shackley, S., Deanwood, R., 2002. Stakeholder perceptions of climate change impacts at the regional scale: implications for the effectiveness and local responses. Journal of Environmental Planning and Management 45, 381-402.

Smit, B., Wandel, J., 2006. Adaptation, adaptive capacity and vulnerability. Global Environmental Change 16, 282-292.

Smith, G., 2003. Deliberative Democracy and the Environment. Routledge, London/ New York.

Smith, J.R., Terry, D.J., Manstead, A.S.R., Louis, W.R., Kotterman, D., Wolfs, J., 2007. Interaction effects in the theory of planned behavior: the interplay of self-identity and past behavior. Journal of Applied Psychology 37, 27262750.

Sterman, J.D., Sweeney, L.B., 2007. Understanding public complacency about climate change: adults' mental models of climate change violate conservation of matter. Climatic Change 80, 213-238.

Stern, N., 2006. The Stern Review on the Economics of Climate Change: Final Report. HMRC, London.

Thompson, D.F., 2008. Deliberative democratic theory and empirical political science. Annual Review of Political Science 11, 497-520.

Tompkins, E.L., Adger, W.N., 2003. Building resilence to climate change through adaptive management of natural resources. Tyndall Centre for Climate Change Research Working Paper Series 27.

Tompkins, E.L., Adger, W.N., Boyd, E., Nicholson-Cole, S., Weatherhead, K., Arnell, N.A., 2010. Observed adaptation to climate change: UK evidence of transition to a well-adapting society. Global Environmental Change 20, 627-635.

Tranter, B., 2011. Political divisions over climate change and environmental issues in Australia. Environmental Politics 20, 78-96.

Vincent, K., 2007. Uncertainty in adaptive capacity and the importance of scale. Global Environmental Change 17.

Wolf, J., Brown, K., Conway, D., 2009. Ecological citizenship and climate change: perceptions and practice. Environmental Politics 18, 503-521.

Wood, B.D., Vedlitz, A., 2007. Issue definition, information processing, and the politics of global warming. American Journal of Political Science 51, 552568. 